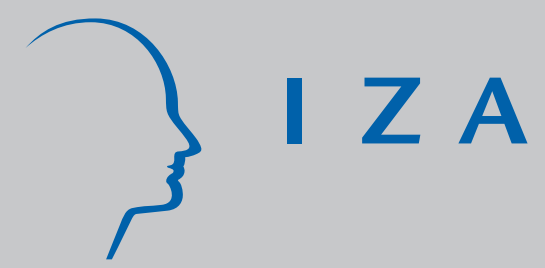

IZA DP No. 8409

Immigration, Cultural Distance and Natives' Attitudes Towards Immigrants: Evidence from Swiss Voting Results

Beatrice Brunner

Andreas Kuhn

August 2014

Forschungsinstitut zur Zukunft der Arbeit Institute for the Study of Labor 


\title{
Immigration, Cultural Distance and Natives' Attitudes Towards Immigrants: Evidence from Swiss Voting Results
}

\author{
Beatrice Brunner \\ ZHAW Zurich University of Applied Sciences \\ and University of Zurich
}

Andreas Kuhn

Swiss Federal Institute for Vocational Education and Training, University of Lucerne and IZA

\author{
Discussion Paper No. 8409 \\ August 2014
}

\author{
IZA \\ P.O. Box 7240 \\ 53072 Bonn \\ Germany \\ Phone: +49-228-3894-0 \\ Fax: +49-228-3894-180 \\ E-mail: iza@iza.org
}

\begin{abstract}
Any opinions expressed here are those of the author(s) and not those of IZA. Research published in this series may include views on policy, but the institute itself takes no institutional policy positions. The IZA research network is committed to the IZA Guiding Principles of Research Integrity.

The Institute for the Study of Labor (IZA) in Bonn is a local and virtual international research center and a place of communication between science, politics and business. IZA is an independent nonprofit organization supported by Deutsche Post Foundation. The center is associated with the University of Bonn and offers a stimulating research environment through its international network, workshops and conferences, data service, project support, research visits and doctoral program. IZA engages in (i) original and internationally competitive research in all fields of labor economics, (ii) development of policy concepts, and (iii) dissemination of research results and concepts to the interested public.
\end{abstract}

IZA Discussion Papers often represent preliminary work and are circulated to encourage discussion. Citation of such a paper should account for its provisional character. A revised version may be available directly from the author. 


\section{ABSTRACT \\ Immigration, Cultural Distance and Natives' Attitudes Towards Immigrants: Evidence from Swiss Voting Results}

We combine community-level outcomes of 27 votes about immigration issues in Switzerland with census data to estimate the effect of immigration on natives' attitudes towards immigration. We apply an instrumental variable approach to take potentially endogenous locational choices into account, and we categorize immigrants into two groups according to the cultural values and beliefs of their source country to understand how the cultural distance between natives and immigrants affects this relationship. We find that the share of culturally different immigrants is a significant and sizable determinant of anti-immigration votes, while the presence of culturally similar immigrants does not affect natives' voting behavior at all in most specifications. The cultural distance between immigrant and native residents thus appears crucial in explaining the causal effect of immigration on natives' attitudes towards immigration, and we argue that the differential impact is mainly driven by natives' concerns about compositional amenities. We finally show that the elasticity of the share of right-wing votes in favor of the Swiss People's Party is much more elastic with respect to the share of culturally different immigrants than natives' attitudes themselves, suggesting that the party has disproportionally gained from changes in attitudes caused by immigrant inflows.

JEL Classification: D72, F22, J15, J61, R23

Keywords: immigration, attitudes towards immigration, voting behavior, cultural values and beliefs, cultural distance, endogenous residential choice, instrumental variable, rightwing votes

Corresponding author:

Andreas Kuhn

Swiss Federal Institute for Vocational Education and Training

Kirchlindachstrasse 79

3052 Zollikofen

Switzerland

E-mail: andreas.kuhn@ehb-schweiz.ch

\footnotetext{
* We thank Armin Falk, Andrea Ichino, Rafael Lalive, Kevin Lang, Rainer Winkelmann, Josef Zweimüller, as well as participants at the 11th IZA Annual Migration Meeting 2014 in Bonn and seminar participants in Zurich for many helpful comments and constructive suggestions. We also thank Sandro Favre and Kathrin Koller for great research assistance. Financial support by the Austrian Science Fund (FWF) is gratefully acknowledged (S10304-G16: "The Austrian Center for Labor Economics and the Analysis of the Welfare State").
} 


\section{Introduction}

Globalization and the internationalization of labor markets, accompanied and in part made possible by enhanced and massively cheapened transport and communication technology, have made the emigration from less developed and even the most remote countries possible in recent years. As a result, international migration is increasing not only in scale, but also in the cultural diversity of the groups involved in that movement (Hugo, 2005; OECD, 2013). As a consequence, many host countries are faced with increasing levels of social and cultural diversity that may cause social tensions and stir up anti-immigration sentiments among native residents, even in the absence of any negative labor-market effects. Indeed, recent survey data show that negative attitudes towards immigration are widespread in many European countries (e.g. Card et al., 2012). Moreover, a series of empirical studies, discussed in more detail below, has shown that immigrant inflows have boosted the support for right-wing parties in several European countries. These parties have set more restrictive immigration policies on the top of their agenda and, in some cases, even try to deliberately fuel anti-immigration feelings among natives. Obviously, knowing about the existence and the size of, as well as about the reasons for attitudinal responses among natives to immigrant inflows, is of utmost importance for both immigration and labor-market policy.

In this paper, we add to this important discussion and present new estimates of the causal effect of immigrant density and heterogeneity on natives' attitudes towards immigration. To this end, we combine community-level results from various votes covering a wide range of immigration policies - ranging from initiatives that aimed at directly restricting the number of immigrants to the vote about signing the bilateral agreement with the European Union regulating the free movement of persons - that were held sometime between 1970 and 2010 in Switzerland with a rich set of community characteristics, calculated from the universe of individual-level data of the Swiss census covering the same time period. Our study expands previous empirical evidence mainly on the following two dimensions. First and foremost, instead of using attitudinal survey data which is prone to various biases, we take advantage of Switzerland's system of direct democracy, where citizens are regularly asked to vote on specific immigration issues and policies. We transform these voting results into shares of anti-

immigration votes and use them as a direct measure of attitudes towards immigration. Using 
actual voting outcomes instead of stated attitudes has not only the advantage of bypassing so-called hypothetical bias, it has also the advantage of not being subject to social desirability. ${ }^{1}$ Moreover, note that our outcome measure is not subject to potential interpretational difficulties due to policy bundling either. ${ }^{2}$ This distinguishes our analysis from studies that use election outcomes, i.e. vote shares in favor of right-wing parties, as the dependent variable in the empirical analysis. As we will show later on, the choice of the dependent variable turns out to be quantitatively, though not qualitatively, important, in the case of Switzerland (in fact, we believe that this is the first study to report estimates that are directly comparable). The second key feature of our study is that we focus on understanding how natives' cultural identity, and the cultural distance between immigrants and natives, might help us understand this relationship. For this purpose, we differentiate between immigrants with a value system similar to Swiss natives, culturally similar immigrants, and immigrants with a different value system, culturally different immigrants. We hypothesize that immigrants are perceived as a threat to natives' national and cultural identity (which we understand as including their language, their system of values and beliefs, as well as their way of life in general) and that the perceived threat increases in the cultural distance between natives and immigrants. We expect that Swiss citizens residing in municipalities with a higher immigrant share are more likely to vote in favor of a more restrictive immigration policy, and that this effect is more pronounced the larger the fraction of culturally different immigrants among the overall immigrant population.

Our study adds to and expands previous evidence on the impact of immigration and attitudes towards immigrants. In terms of the outcome variable, our focus on voting results as a direct measure of natives' attitudes towards immigration is unique, as we are only aware of one

\footnotetext{
${ }^{1}$ Hypothetical bias circumscribes the fact that individuals have virtually no incentive to reveal their true preferences in a typical survey setting because doing has no real consequences (e.g. Miguet, 2008). In addition, it has also been argued that the political discussion preceding a vote enables individuals to make a better informed decision on the issue than when asked to answer an abstract survey item (Benz and Stutzer, 2004). Moreover, when faced with hypothetical evaluations, individuals may decide to stick with answers that they think are socially accepted (e.g. Bertrand and Mullainathan, 2001). Both effects are likely to work in favor of finding (too) positive attitudes to immigration. In contrast, it is much more likely that voting results reflect true sentiments toward immigration because the result is binding and thus has real consequences and because, moreover, voting is anonymous.

${ }^{2}$ Votes in favor of right-wing parties may be a blurred measure of natives' attitudes towards immigration in case that individuals have different motives for supporting these parties. Most importantly, most rightwing parties not only lobby for stricter immigration polices, but also distinctly try to cut back redistributive polices, which may make it difficult to distinguish between attitudes towards immigration and attitudes towards redistribution (Lee and Roemer, 2006).
} 
single study also investigating the relationship between immigrant density and voting results (Tolbert and Hero, 1996). This study analyzes the voting results about California's illegal immigration initiative and finds that, somewhat surprisingly perhaps, not only counties with large Latino populations, but also counties with predominantly white population strongly supported the initiative. However, the analysis does not properly address the potential endogeneity of local immigration shares and does, therefore, not yet establish fully credible evidence of a causal relationship. ${ }^{3}$ In fact, a similar concern applies to most previous, primarily sociological, studies that have tried to estimate the impact of immigration on natives' attitudes towards ethnic minorities or immigration (e.g. Quillian, 1995; Schneider, 2008; Semyonov et al., 2006). As a consequence, one should be somewhat cautious when interpreting the findings of this strand of the literature (the general finding in this literature being a positive association between immigrant shares and anti-foreigner sentiments among natives). Other authors have been more aware of, and sensitive to, these identification issues, however. One notable exception amongst the studies working with attitudinal data is the study by Dustmann and Preston (2001), who find that the bias resulting from the neglect of the endogeneity of residential choices is negative and quantitatively important, as estimates that take endogenous locational choices into account are up to four times larger than naive estimates that ignore such biases. Similar emphasis on potential identification issues due to endogenous locational choices has been given in a series of closely related empirical studies on the impact of local immigrant shares on natives' support for right-wing parties which are, often very fiercely, pushing more restrictive immigration policies. Both Gerdes and Wadensjö (2008) and Harmon (2012) study the impact of local immigrant densities on votes in favor of right-wing parties in Denmark, and both studies find that increases in local immigrant populations lead to corresponding increases in the support for anti-immigration parties. A similar finding is reported in a study of city districts in Hamburg, Germany, by Otto and Steinhardt (2014), who find that increases in local immigrant shares lead to significant increases in the number of right-wing votes, as well as by Halla et al. (2012), who present evidence of a significant positive effect of local immigrant shares on votes in favor of the right-wing FPÖ at elections of the national parliament in Austria. Barone et al. (2014) find similar results for Italy, while Mendez and Cutillas (2014) report somewhat contrasting

\footnotetext{
${ }^{3}$ Besides the difference in the empirical approach, note that Tolbert and Hero (1996) focus on one specific vote, while we have assembled data on 27 different votes about diverse immigration, naturalization, and asylum policies (as discussed in more detail below), spread across five consecutive decades.
} 
evidence for Spain in that they find only weak effects of immigrant inflows on right-wing party preferences among natives.

Our paper also relates to the literature which studies why immigration affects natives attitudes to immigration, especially to more recent studies arguing that less tangible factors besides concerns about increased labor-market competition from immigration or welfare concerns are presumably a crucial factor in shaping attitudes towards immigration among natives. Indeed, the available evidence on the importance of economic concerns turns out to be surprisingly ambiguous. Some studies find that fears about increased labor market competition strongly shape individual attitudes towards immigrants (e.g. Mayda, 2006; Scheve and Slaughter, 2001), other studies find either no or only weak evidence for this channel (Card et al., 2012; Hainmueller and Hiscox, 2010; O'Connell, 2011) or that such concerns are not a significant determinant of natives' attitudes once unobserved cultural values and beliefs are taken into account (Hainmueller and Hiscox, 2007; Müller and Tai, 2010). ${ }^{4}$ In contrast, more recent empirical evidence has focused on the possibility that natives' opposition towards further immigration is increasing in the ethnic distance between natives and immigrants (Card et al., 2012; Dustmann and Preston, 2007; Mendez and Cutillas, 2014). For example, in their analysis covering survey data from several European countries, Card et al. (2012) conclude that concerns about compositional amenities are two to five times as important as economic concerns. In our own empirical analysis, we will build on this latter evidence and study whether the cultural distance between immigrants and natives might help us to understand how the presence of immigrants shapes natives' attitudes towards immigrants, arguing that cultural concerns - rather than concerns about labor-market competition - drive any observed different in the impact between the two groups of immigrants.

The remainder of this paper is organized as follows. In section 2 we briefly explain why we expect the cultural distance between immigrants and natives to be important in shaping natives' attitudes towards immigration and describe how we implement the concept empirically. In section 3 we discuss the sources and the structure of our data, as well as the construction of our key variables. We also present some descriptive statistics in this section, highlighting the

\footnotetext{
${ }^{4}$ The fact that the evidence with respect to the importance of labor market competition in shaping natives' attitudes to immigration is ambiguous squares well with the fact that many empirical studies tend to find modest or weak average labor-market effects of immigration. At the same time, it appears somewhat less contentious that fears related to welfare concerns (i.e. immigrants disproportionally entering the social welfare system) play an important role in the formation of attitudes (Dustmann and Preston, 2006, 2007; Müller and Tai, 2010).
} 
most salient features of immigration to and natives' anti-immigration sentiments in Switzerland. Section 4 presents the econometric framework and explains our identification strategy. In section 5 we present and discuss our estimates regarding the relation between local immigrant shares and natives' attitudes towards immigration, along with a variety of alternative specifications and different robustness checks. Section 6 present results that address potential concerns regarding lack of external validity of our results due to participation bias. In section 7 we show how immigration affects the vote share in favor of the right-wing Swiss People's Party, and compare the effect on right-wing vote shares with the effect on attitutdes. In section 8 we summarize our findings and discuss potential implications for immigration and labor-market policy in Switzerland and other immigration countries.

\section{Cultural distance between natives and immigrants}

While increased labor-market competition due to immigration, whether real or perceived, may be important in shaping natives' attitudes towards immigration, we believe that a more direct, and potentially much more powerful, mechanism acts through natives' cultural identity (Akerlof and Kranton, 2000, 2010). In the context of how native residents feel and think about immigrants, we argue that individuals's cultural or national identity is, first and foremost, tied to their language, their lifestyle, their customs, as well as their set of cultural values and beliefs more generally. Accordingly, a native's identity of him- or herself may be threatened by the mere presence of immigrants because they challenge a native's system of cultural values and beliefs, which in the absence of immigrants (i.e. in the absence of alternative values and belifes) is taken-for-granted. Recent empirical evidence on the importance of compositional amenities (Card et al., 2012), such as concerns about the composition of one's residential neighborhood (Li, 2014; Saiz and Wachter, 2011) and especially concerns related to school and class composition of one's children (Cascio and Lewis, 2012), in shaping natives' attitudes to immigrants appears perfectly consistent which such a line of argument. In what follows, we thus presume that immigrants threaten natives' identity because they speak a different language, have a distinct lifestyle, and because they adhere to cultural values and beliefs different from those of native residents, which in turn may manifest itself in negative attitudes towards immigration among native residents. Moreover, we also hypothesize that the threat to natives' identity is 
the more salient and the more intense the greater the cultural distance between immigrants and natives. For this reason, we expect the negative impact of local immigrant inflows to increase in the cultural distance between immigrants' country of origin and Switzerland. ${ }^{5}$

Obviously, there are various ways to empirically explore the potential importance of the cultural distance between natives and immigrants, but for the main part of our analysis we will rely on a simple binary classification of immigrants derived from the key findings of an influential study by Inglehart and Baker (2000). Using data from the Word Value Survey, they isolate two major value dimensions from a large variety of cultural items and locate each country on these two value dimensions, explaining roughly $70 \%$ of the variation in country averages of the underlying attitudinal survey items. The first dimension reflects the importance of traditional - as opposed to secular-rational - values, with the former emphasizing the importance of religion, parent-child-ties, and a general deference to authority (secular-rational values, in contrast, emphasize values such as gender equality and tolerance of human diversity, such as tolerance of homosexuality). The second dimension is linked to the rise of a postindustrial society in which an increasing share of the population grows up taking survival for granted and which, as a consequence, attaches increasing emphasis on subjective well-being, personal self-fulfillment and self-expression (survival vs. self-expression values).

In our own analysis we will separate immigrants into two different groups based on the cultural heritage of their country of origin as captured by the two dimensions identified by Inglehart and Baker (2000). For the most part of the analysis, we simply differentiate between two groups of immigrants: immigrants with a similar value system as Swiss natives and immigrants who contrast with the Swiss value system, on at least one of the two dimensions mentioned above. The first group of immigrants, culturally similar immigrants in what follows, encompasses immigrants from historically protestant and catholic non ex-Communist countries as well as immigrants from the English-speaking OECD countries. These countries share Swiss natives' values and beliefs by and large, according to the findings of Inglehart and Baker (2000), and they are characterized by the relative importance of secular-rational (as opposed to traditional) and self-expression (as opposed to survival) values. The second group

\footnotetext{
${ }^{5}$ Note that the proposed mechanism presupposes that there is a substantial degree in intergenerational persistence in immigrants' cultural identity (similar to, for example, Fernández and Fogli, 2006). A recent study by Casey and Dustmann (2010) presents direct evidence of strong intergenerational persistence of identity among immigrants in Germany.
} 
of immigrants, culturally different immigrants, is composed of all the remaining immigrants from countries that differ either on one or on both of the two cultural dimensions from Swiss natives' value system. This group includes immigrants from former Communist countries, such as former Yugoslavia, as well as immigrants from Afria, Asia, or South America.

When discussing the robustness of our main results, however, we also show results that use a slightly different categorization of immigrants, based on either the linguistic or, alternatively, the religious distance between immigrants and natives. In the former case, we will contrast immigrants speaking one of Switzerland's native languages also spoken in other countries (i.e. either German, French, or Italian) with those speaking any other language; in the latter case we will contrast immigrants from countries with a predominantly Christian denomination (Switzerland's main denomination is Protestantism in some, Catholicism in other parts of the country) with those from any other religion.

\section{Data}

We draw data from two different sources. First, we use the official results from various national votes on specific immigration policies in Switzerland, which are available at the level of the community, as our direct measure of natives' attitudes towards immigration. Our second source of information is the universe of individual-level data from the decennial Swiss census. We use the census data to compute local immigrant shares as well as various other municipality-level characteristics, which can then be merged with the voting results. However, while votes may take place on any given year, census data are only available every ten years. To still be able to exploit the whole range of votes, we decided to merge each vote to the year of the nearest census (for example, we merge the results on a vote held in 1974 with census data from the year 1970). Obviously, due to their distinct longitudinal structure, there are alternative ways of merging the two data sources together, but fortunately our results turn out to be insensitive to the exact way we merge the two data sources together. ${ }^{6}$

\footnotetext{
${ }^{6}$ Specifically, we obtain similar results when votes taking place in the 1970s are merged with the 1970 census, and similarly for the other decades (results not shown). More importantly, however, we also get very similar results when we aggregate all data by decade (see section 5.2 below for details).
} 


\subsection{National votes on immigration policies and natives' attitudes towards immigration}

Voting outcomes are available at the municipality-level from 1970 onwards, and they contain information on the percentage share of affirmative votes as well as on voter turnout. ${ }^{7}$ Table 1 presents some information on all of the 27 votes about immigration policies that were held at the national level and in the time period considered. Note that the different votes deal with very diverse issues, even though there are several recurrent themes (i.e. immigration control, legislation ruling the naturalization of immigrants, and asylum law). What all these votes have in common, however, is that the outcome of the vote has potentially far-reaching consequences for resident and/or prospective immigrants and, in many cases, for natives as well.

Table 1

In what follows, we will use the community-level results of all the votes from table 1 to construct our measure of natives' attitudes to immigration. As apparent from the table, however, acceptance of a vote sometimes means a liberal opinion towards immigration, sometimes it means the opposite. To make the various votes comparable, we thus use the share of antiimmigration votes, i.e. the share of votes in favor of a more restrictive immigration policy, as our dependent variable (for each vote, column five of table 1 therefore indicates whether or not an affirmative vote implied support for a more restrictive immigration policy). ${ }^{8}$

\subsection{Community characteristics from the Swiss population census}

We complement the municipality-level voting results on immigration policies with local immigrant shares as well as with various other community-level characteristics calculated from the

\footnotetext{
${ }^{7}$ The Swiss foundation for research in social sciences provides the results of all national votes that took place in Switzerland between 1970 and 1981. Starting in 1981, voting results are provided by official statistics from the Federal Statistical Office (FSO). Voting results prior to 1981 could no longer be reconstructed on the municipal, but only on the cantonal level for three (Aargau, Freiburg and Tessin) of the 26 cantons (i.e. Swiss states).

${ }^{8}$ While our measure of natives' attitudes to immigration has a couple of important advantages compared to other measures used in the literature, especially those based on survey items, we acknowledge that there are a few potential concerns as well. A first concern relates to the fact that the votes deal with different subjects and that, for this reason, it may not be suitable to combine the different votes into one and the same dependent variable. A closely related issue is that not only the level, but also the variation in a community's approval of a vote may vary across votes (reflecting that some votes are more controversial than others, for example). A somewhat more subtle issue concerns the fact that voter turnout does also vary across votes, implying that there might be an issue with varying sample composition across the different votes. We will tackle all of these potential issues later on in section 5.2 .
} 
universe of individual-level data of the decennial Swiss population census. The census data are by definition virtually complete, and the high quality of the data allows us to neglect problems of measurement error. ${ }^{9}$

In addition to extensive information on individual socio-economic characteristics (such as age, gender, employment status, or religious affiliation), the population census reports the country of origin for each foreign born person residing in Switzerland. In the following, and in accordance with Swiss legislation, an immigrant is defined as any resident without Swiss citizenship. ${ }^{10}$ In the empirical analysis below, we focus on either the overall immigrant share or on culture-specific immigrant shares, as conceptualized in section 2.

\section{Spatial structure of the data}

We will also use variables representing information that has been aggregated using different geographical units in the econometric analysis. It is therefore helpful to briefly discuss the spatial structure of our data (see Schuler et al., 2005, for details). Our basic unit of observation is the community, the smallest spatial unit with significant political autonomy in Switzerland. We deal with changes in the municipality structure over time (mainly due to smaller communities merging with each other) by creating a balanced panel of municipalities based on a slightly modified version of the territorial boundaries of the year 2000, thus keeping the definition of geographic units constant across time. Our final dataset represents a strongly balanced panel encompassing a total of 2,544 communities and a total of 68,688 observations $(=27$ votes $\times$ 2,544 municipalities).

While communities represent our primary units of observation, we will also use information that relates to broader geographical units. First there are so-called ms-regions (ms stands for "mobilité spatiale", or spatial mobility), whose boundaries are defined by the Federal Statisti-

\footnotetext{
${ }^{9}$ The main drawback of the census data is a structural break between 2000 and 2010 because the Federal Statistical Office decided to switch to an annual survey starting in 2010, mainly drawing on existing information from administrative data (in practice, one expects structural breaks in at least some of the variables). Moreover, because the data were not yet available when preparing this paper, we decided to impute the missing values of the control variables with their values from the preceding census of the year 2000. Importantly, however, note that we work with actual, not imputed, immigrant shares because this information was already available from official statistics at our desired level of aggregation. See section 5.2 below for corresponding robustness tests.

${ }^{10}$ In contrast to other countries, such as the United States, citizenship in Switzerland does not depend on place of birth. Thus many of those legally defined as immigrants are actually born in Switzerland, at least in more recent years. In this context, it is interesting to point out that several of the votes listed in table 1 have tried to either ease or tighten the rules governing access to Swiss citizenship.
} 
cal Office based on the observed level of economic interactions and actual commuting patterns of the workforce, and thus they may be best thought of as representing local labor markets. Switzerland is divided into 106 such regions, each encompassing an average of 24 communities. Second, there are 26 cantons in Switzerland, each encompassing an average geographical area of about four ms-regions and 98 communities. Unlike local labor markets, cantons are subnational entities with far-reaching autonomy in, for example, taxation and educational policy. Finally, the seven NUTS-2 regions represent larger catchment areas of Switzerland's main economic centers, each encompassing more than 360 communities on average (for example, the metropolitan region of Zurich represents one such region).

\subsection{Descriptives}

Figure 1 visualizes the two most salient features of Switzerland's immigration experience since the 1970s (cf. Gross, 2006, 2012). First, as illustrated in the upper panel of figure 1 (darker shaded areas represent communities with higher immigrant shares), the overall immigrant share in Switzerland has substantially increased over the considered period, starting from an already high level in the 1970s, in comparison to most other Western European countries, from $17.2 \%$ in 1970 to $22.5 \%$ in 2010 (a relative increase of about one third). As the figure suggests, Switzerland indeed experienced the largest inflows of immigrants in the 1950s and 1960s already.

Figure 1

The second important feature, evident from the lower panel of figure 1, is the large increase in the relative number of culturally different immigrants (darker shaded areas representing communities with a larger fraction of culturally different immigrants). Indeed, the fraction of culturally different immigrants among all immigrants has been low in most Swiss communities in 1970, with an overall average fraction of culturally different immigrants of about $8.6 \%$ only. Until the year 2010, however, this number has more than quadrupled, to an overall average of about $37.5 \%$. Thus Switzerland has indeed, like many other European countries with net immigrant inflows, experienced a significant and substantial change towards increased ethnic diversity in the composition of its immigrant population.

Table 2 
Table 2 has a closer look at how the composition of immigrants has changed over time and, to this end, shows the distribution of immigrants according to their country or region of origin (upper panel A) as well as overall and culture-specific immigrant densities (lower panel B). ${ }^{11}$ Looking at the regional composition of immigrants first, one notable feature is that immigrants from a few countries made up the vast majority of all immigrants in 1970. Also, there were only few immigrants from outside Europe, accounting for only $3.8 \%$ of all immigrants in that year. This picture has significantly changed over time, however. The most notable shifts in the composition of immigrants relate to a large influx of immigrants from former Yugoslavia during the Balkan wars, as well as the significant increase in the share of immigrants from both Germany and Portugal in more recent years. The increase in the heterogeneity of immigrants to Switzerland is perhaps best illustrated by the huge increase in the percentage share of immigrants from outside Europe, however, which has increased more than five-fold within our observation period - from a mere $3.8 \%$ in 1970 to slightly more than $21 \%$ in 2010 .

Panel B of table 2 shows that these changes in the composition of immigrants are associated with substantial increases in the cultural distance between immigrants and natives. In fact, the share of immigrants with a different cultural background has increased considerably faster than the overall immigrant share - the fraction of culturally different immigrants among all immigrants has increased from a mere $8.3 \%$ in 1970 to $38.8 \%$ in 2010.

\section{Figure 2}

Moving on to natives' attitudes to immigration, figure 2 shows the spatial distribution of anti-immigration votes in both 1970 and 2010 (darker shaded communities are those with more hostile attitudes to immigration). Again, several features stand out very clearly. First, the share of anti-immigration votes has significantly increased over time, starting from a mean level of anti-immigration votes of about $41 \%$ in 1970 to a mean of about $52 \%$ in 2010 . Second, while higher levels of anti-immigration votes have largely been confined to rural areas in 1970 (mainly, but not exclusively, Central Switzerland), this is not true anymore in more recent years. As of 2010, anti-immigration votes appear to be much more broadly spread across the country, except for the larger urban areas such Berne or Zurich. Moreover, in the year 2010,

\footnotetext{
${ }^{11}$ Interestingly, the classification of immigrants' country/region of origin used by the Federal Statistical Office has changed over time as well, paralleling the increasing heterogeneity of immigrants. The classification used in table 2 is essentially based on the classification of immigrants that was used in the 1970 census.
} 
there is another obvious trench in anti-immigration votes between the French-speaking part of the country (located in the East) the German- and Italian-speaking part of Switzerland (located in the West and the South of the country).

\section{Econometric framework}

\subsection{Estimating the impact of immigration on natives' attitudes}

We next discuss the econometric framework which we use to eventually pin down the causal effect of local immigrant shares on natives' anti-immigration attitudes. We initially start with the assumption that locational choices are exogenous, implying that immigrant shares can be treated as exogenous in the empirical analysis, but we will relax this critical assumption soon after. Our initial regression model takes the following basic form:

$$
\begin{aligned}
& A I V_{j v[t]}=\alpha+\beta^{o} I_{j T[t]}^{\text {overall }}+\gamma Z_{j T[t]}+\delta X_{j T[t]}+\psi_{n[j] v[t]}+\epsilon_{j v[t]}, \quad \text { or } \\
& A I V_{j v[t]}=\alpha+\beta^{s} I_{j T[t]}^{\text {similar }}+\beta^{d} I_{j T[t]}^{\text {different }}+\gamma Z_{j T[t]}+\delta X_{j T[t]}+\psi_{n[j] v[t]}+\epsilon_{j v[t]},
\end{aligned}
$$

with $A I V_{j v[t]}$ denoting the share of anti-immigration votes in municipality $j$ with respect to vote $v$ taking place in year $t$ (note that we have to distinguish between votes and years since there are several occasions with more than one vote in the same year; cf. table 1). In our first specification, the overall immigrant share $I_{j T[t]}^{\text {overall }}$ in municipality $j$ in census year $T$ (which is closest to the year $t$ in which vote $v$ effectively took place) is the regressor of main interest. In the second, more elaborate specification we split the overall immigrant share into the two culture-specific local immigrant shares, as defined in section 2. Thus $\beta^{o}$ and $\left[\beta^{s}, \beta^{d}\right]$, respectively, is the parameter (parameter vector, respectively) of key interest, capturing the partial effect of the local immigrant share(s) on the share of anti-immigration votes among native residents (note that a positive sign of $\widehat{\beta}^{c}$, with $c \in\{o, s, d\}$ ) implies that larger immigrant shares are associated with more intense anti-immigration votes).

The full-blown version of equation (1a) and (1b), respectively, serves as our baseline specification and contains a variety of control variables. First, $Z_{j T[t]}$ comprises several residential area characteristics which can best be thought of as essentially fixed locational characteristics of a given community $j$. More specifically, $Z_{j T[t]}$ includes the fraction of a community's area which 
is urbanized, the share of its resident population speaking one of the Swiss native languages (i.e. German, French, Italian, or Romansh), and whether municipality $j$ is a border community (i.e. whether community $j$ borders a foreign country). ${ }^{12}$ In addition, vector $X_{j T[t]}$ includes a number of variables describing a community's native residents. It contains the following aggregated socio-economic characteristics of Swiss citizens: the distribution of labor market status (the share of individuals employed, unemployed, or not employed); the distribution of occupational status (the share of individuals who are self employed, employed by a family member, a trainee, in a management or non-management position); the distribution of highest educational attainment (the share of individuals with primary-, secondary- or tertiary-level education); the distribution of marital status (the share of individuals who are single, married, and widowed or divorced); mean age and mean age squared; the share of female individuals; the distribution of religious affiliation (the share of Protestants, Catholics, Jews, Moslems, and individuals with any other or no denomination at all) and the share of foreign born Swiss citizens. The full-blown version of equation (1a) or (1b) also includes NUTS-2 specific vote fixed effects, denoted by $\psi_{n[j] v[t]}$, with $n$ indexing the NUTS-2 region a given community $j$ makes part of. This eliminates all time-varying unobserved heterogeneity between the seven catchment areas of Switzerland's main economic centers and is also expected to eliminate much of the potential bias due to unobserved and time-variant variables.

Finally, we weight the observations with the size of the local native voting population in most specifications, and we cluster standard errors by municipality throughout due to the fact that the key regressor varies at a higher aggregation level than the dependent variable (Moulton, 1990) as well as to allow for arbitrary serial correlation in the error term across votes (i.e. across time) within the same community (Bertrand et al., 2004).

\subsection{Endogenous locational choices}

However, because individuals are free to choose their neighborhood, local immigrant shares in an individuals' municipality are unlikely to be exogenous in the presence of natives' concerns about cultural identity. Quite in contrast, it seems much more reasonable to assume that xenophobic natives are unlikely to locate in municipalities with a large immigrant population

\footnotetext{
${ }^{12}$ Almost all of these variables have autocorrelation coefficients close to 1 , which empirically underlines our claim that they basically represent fixed characteristics of the community itself, and not so much characteristics of a community's residents.
} 
and to outflow of communities with a high immigrant density. By the same token, it also seems unlikely that immigrants will decide to settle in areas where they expect racial discrimination. In fact, there is ample empirical evidence in support of endogenous locational choice of both natives and immigrants (Card et al., 2008; Damm, 2009; Saiz and Wachter, 2011; Wong, 2013). In such circumstances, it is well understood that ordinary least-squares (OLS) estimates of parameter (vector) $\beta^{c}$ in equation (1a) or (1b) are likely to be downward biased and inconsistent, even in the presence of fixed effects.

\section{Immigrant shares in local labor markets as instruments}

In order to obtain a consistent estimate of the impact of immigration on voting results in spite of endogenous settlement choices, we thus apply an instrumental variable approach in the second step of our empirical analysis. Following Dustmann and Preston (2001), we instrument the municipal immigrant share with the immigrant share in a broader geographical area, i.e. in an area which encompasses several communities. More specifically, we use the immigrant shares in the local labor markets (i.e. ms-regions) as our instrument because they are based on actual commuting patterns and thus best comply with the requirements for a valid instrument, as will soon become clear. Our first-stage regression thus looks as follows:

$$
I_{j T[t]}^{c}=\pi_{0}+\pi_{1}^{c} I_{l[j] T[t]}^{c}+\pi_{2} Z_{j T[t]}+\pi_{3} X_{j T[t]}+\psi_{n[j] v[t]}+\varepsilon_{j v[t]},
$$

with $I_{l T[t]}^{c}$ representing either the overall immigrant share or the two cultural-specific immigrant shares in census year $T$ and local labor market $l$ to which municipality $j$ belongs to (again, note that the number of local labor markets, $L$, is much smaller than the number of communities, $J)$. The list of controls and the weighting scheme are exactly the same as when estimating equation (1a) or (1b) by OLS. In contrast to above, however, we cluster standard errors by local labor markets when estimating using two-stage least squares (2SLS) because the instrument varies at that higher level of aggregation only.

The key identifying assumption underlying the outlined procedure is that the immigrant share in the larger geographic region (i.e. local labor markets) is determined by factors other than by native residents' anti-immigration attitudes. Put differently, we have to assume that mobility motivated by ethnic or cultural concerns only exists within, but not across local labor 
markets. One way to argue in favor of this assumption is that individuals, when choosing their place of residence, first decide upon a larger geographic region based on the availability of job opportunities or the closeness of one's family and friends. Crucially, however, residential choice must not depend on attitudes towards immigration at this stage. Only later, when it comes to decide upon the local neighborhood within the larger settlement region, may the immigrant composition become part of the decision. While this identifying assumption is not directly testable, we can still probe its potential validity to a limited extent because some implications of the identifying assumption are empirically testable with the data at hand. We will provide such a test in section 4.3 below, estimating the impact of changes in the municipal immigrant share on natives' residential mobility (i.e. natives' outflow pattern). The findings from this test lead us to conclude that the immigrant share in the ms-region is uncorrelated with natives' migration pattern. Consequently, we believe that $I_{l[j] T[t]}^{c}$ is a valid instrument for $I_{j T[t]}^{c}$ because sorting within local labor markets, which is that part of the settlement decision that can depend on attitudes, does not alter the overall ethnic composition within local labor markets. Further empirical support in favor of this instrument is provided in section 4.3 below.

However, identification further requires that the instrument has no direct effect on natives' voting behavior, and that the instrument is partially correlated with the endogenous variable. The latter assumption simply implies that $\pi_{1}^{c}$ in equation (2) must be nonzero, which can easily be checked when estimating the first-stage regression, while the former implies that an individual's attitude toward immigration must depend solely on the immigrant concentration in the immediate vicinity (i.e. municipality), but not on the immigrant share within the local labor market. We are aware that this assumption is not innocuous and that it may fail, for example, for native workers who do not work and live in the same community. In such a case the worker's attitudes towards immigration may be influcened not only by the immigrant share of the community he lives in but also by the immigrant share of the community where his workplace is located. In such a scenario, our 2SLS estimates will probably overestimate the causal effect of the communal immigrant share on natives' attitudes due to a direct effect of the instrument on the dependent variable (e.g. Angrist and Krueger, 1994). It is for this reason that we will present estimates that use an alternative instrumental variable as well. 


\section{Immigrants' historical settlement pattern as an alternative instrument}

Complementing our main estimates, we will thus also present additional estimates that use the historical settlement pattern of immigrants as an alternative instrument (e.g. Altonji and Card, 1991; Card, 2001). This instrument takes advantage of the observation that ethnic networks are important for recent immigrants' locational choices and that immigrants are more likely to settle in areas where there are already people with a similar ethnic or cultural background (e.g. Damm, 2009; Wong, 2013). ${ }^{13}$

Note, however, that this strategy does not allow for any residential mobility response of natives across municipality borders. As a result, using historical migration patterns as an instrument may result in downward biased estimates because the negatively affected individuals are more likely to move to another community. Another drawback of this instrument is that we lose all observations from the first decade because immigrant shares are only available on a decennial basis (i.e. we lose all observations from the 1970s). Considering that our sample covers five decades only, this is a relatively large loss of information. Nonetheless, we do provide these additional estimates as well because we think that they will provide useful insights regarding the plausibility of our main identification strategy. ${ }^{14}$

\subsection{Assessing instrument validity}

As we have just been discussing, identification using immigrant shares at the level of local labor markets as instrument implies that racially motivated mobility by the native population only exist within, but not across, local labor markets. Fortunately, because the census does not only report individuals' place of residence at the time of the survey, but also five years earlier, we can actually test this specific implication of the key identifying assumption by running the following simple regression model:

$$
\mathbf{1}\left(r_{i T} \neq r_{i(T-5)}\right)=\alpha+\beta \Delta I_{j[i] T}^{o}+\gamma_{o} Z_{j[i] T}^{o}+\gamma_{d} Z_{j[i] T}^{d}+\delta X_{i T}+\psi_{k[r] T}+\epsilon_{i T},
$$

\footnotetext{
${ }^{13}$ The key identifying assumption in this case is that past immigration patterns have no direct effect on current attitudes of natives, besides their effect on current immigrant inflows into the community. The identifying assumption is similar (though not identical) to the one invoked by our main identification strategy, and we think that none of the two identifying assumptions is per se more plausible than the other.

${ }^{14}$ In fact, as we will discuss in more detail below, one could even argue that the estimates based on different instruments yield informative bounds on the true effects of immigration.
} 
where the dependent variable is an indicator function taking on the value one if individual $i$ moved within the last five years (i.e. between census year $T$ and $T-5$ ), and zero otherwise. We study both movements across municipalities (i.e. $r=j$ ) as well as across local labor markets (i.e. $r=l$ ). Note that the parameters of equation (3), in contrast to above, are estimated using individual-level data. The two vectors $Z_{j[i] T}^{o}$ and $Z_{j[i] T}^{d}$ contain a few area characteristics (i.e. the unemployment rate, the fraction of the area of a community which is urbanized, and an indicator for whether community $j$ is a border area) of both an individual's origin and destination region of residency, respectively. We also include individual socio-economic characteristics, denoted by $X_{i t}$ (see the description of equation (1a) and (1b) for details).

Parameter $\beta$ is of main interest as it captures how a change in the immigrant share during the last decade in an individual's original resident municipality, $\Delta I_{j[i] T}^{o}$, affects the probability of having left one's municipality $(r=j)$ or one's local labor market $(r=l)$, respectively, within the past five years, i.e. between $T$, the year of the census, and $T-5$. If the identifying assumption holds true, $\beta$ should be close to zero in the case of residential mobility across local local labor markets, while we expect the estimate of $\beta$ to be significantly different from zero in the case of mobility across communities because we expect an outflow of natives in case of large immigrant inflows into any given community.

\section{Table 3}

The resulting coefficient estimates are shown in table 3. These results indeed suggest that an increase in the share of culturally different immigrants causes natives to leave their original municipality of residence, but they provide no evidence for racially motivated mobility effects across local labor markets at the same time. ${ }^{15}$ We interpret this finding as strong evidence in favor of the validity of our identification strategy. Note that this result also implies that instruments that do not allow for mobility responses across municipalities, such as the historical settlement pattern of immigrants, may underestimate the true effect for this reason.

\footnotetext{
${ }^{15}$ Not surprisingly, table 3 also shows that the estimates are essentially the same in terms of marginal effects, regardless of whether equation (3) is estimated by OLS or using a Probit model.
} 


\section{The impact of immigration on natives' attitudes}

\subsection{Main results}

Table 4 presents our main estimates of the impact of local immigrant shares on natives' attitudes to immigration. The table reports estimates of the impact of the overall immigrant share (panel A) as well as of the two culture-specific immigrant shares (panel B) on natives' anti-immigration votes; the first four columns in each panel report OLS estimates, the remaining column shows 2SLS estimates. All specifications include vote fixed effects to net out overall differences in the share of anti-immigration votes due to differences in the subject of the various votes (obviously, any time trend in natives' attitudes to immigration is also netted out this way) and, as mentioned before, all estimates shown in table 4 are weighted by the native voting population size of the municipalities. The first column reports estimates from a simple specification that includes immigrant shares and vote fixed effects only. We add controls for local area and NUTS-2 fixed effects in column 2, controls for socio-economic characteristics of natives in column 3, and we further allow for unobserved heterogeneity within votes (i.e. over time) between different NUTS-2 regions in column 4 by additionally including NUTS-2 specific vote fixed effects. In column 5 we additionally instrument for local immigrant shares using immigrant shares within local labor markets.

Table 4

We first discuss the estimates using the overall immigrant share as main regressor. The first column shows that there is a strong negative and statistically signifcant correlation between anti-immigration votes and the overall immigrant share, net of any differences in attitudes due to differences in the subject of the votes as well as due to any aggregate time trend, implying that anti-immigration votes are more prevalent in communities with lower immigrant density. Once we control for regional and socio-demographic characteristics, however, the coefficient estimate on the overall immigrant share becomes small and statistically insignificant. When we further add NUTS-2 specfic vote fixed effects, we get a statistically significant and positive coefficient estimate of 0.048 (with a robust t-value of about 2.18). Finally, instrumenting the local immigrant share yields a point estimate which is considerably larger, but also much less precise, than its OLS counterpart (point estimate of 0.459 with a robust t-value of about 2.3). 
The corresponding two-stage least squares (2SLS) estimate implies an appromximate elasticity of anti-immigration votes with respect to the overall immigrant share of about 0.167 (evaluated at mean values). Comparing the estimates from column 4 with column 5 suggests that, in line with the results from Dustmann and Preston (2001) and many others, endogenous residential choices are quantitatively important, and that ignoring this issue may lead to severely downward biased estimates of the causal impact of immigration on natives' attitudes towards immigration.

Panel B, in contrast, shows parameter estimates for the impact of both culturally similar and culturally different immigrants on the local share of anti-immigration votes among natives. Across the different specifications, the share of culturally different immigrants turns out to be a significant determinant of natives' anti-immigration votes. Both OLS and 2SLS estimates are positive and statistically significant, but the 2SLS estimates again turn out to be considerably larger than the corresponding OLS estimates. However, not surprisingly, they are also much less precisely estimated than the OLS estimates. The estimates for the share of culturally similar immigrants reveal a qualitatively different pattern. The point estimate is initially negative, but then turns small and statistically insignificant in the specification including the full set of control variables. The estimates using the full set of controls from the last column of table 4 imply that anti-immigration votes within a community increase by a significant 1.153 percentage points (a nonsignificant 0.205 percentage points) when experiencing a one percentage point increase in the share of culturally different (similar) immigrants. These estimates imply an elasticity of anti-immigration votes with respect to the share of culturally different (similar) immigrants of about $0.14(0.05)$ if evaluted at mean values. As for the overall immigrant share, the large positive difference between corresponding 2SLS and OLS estimates is consistent with the idea that settlement decisions are endogenous. Moreover, comparing the estimates from panel A and B clearly shows that ignoring the cultural distance between natives and immigrants masks important differences in the impact on natives' attitudes between different groups of immigrants. Focusing on the last column of table 4 shows that the positive effect of the overall immigrant share on anti-immigration attitudes in our preferred specidication appears to be driven almost entirely by the positive effect of the share of culturally different immigrants. 
Finally, table 4 also reports robust F-statistics from the first-stage regressions associated with each of the endogenous variables in brackets, quantifying the strength of the association of the instruments with the endogenous variables. Note that, in all specifications, the F-statistics are large and well above the rule-of-thumb critical value of 10 suggested by Staiger and Stock (1997), thus alleviating potential weak-instrument concerns. ${ }^{16}$

\subsection{Robustness}

We next provide a series of robustness checks. A first check tests the sensitivity of our estimates with respect to slightly different covariate and fixed effects specifications as well as to the use of alternative instruments. We then provide some additional robustness checks related to data issues such as potential endogeneity of part of the controls or alternative weighting schemes. Third, we check whether our main findings also hold for single votes (this may also be understood as a test of time-varying coefficients). A final check looks at some alternative classification schemes of immigrants.

\section{Specification checks and alternative instruments}

Table 5 presents the results for various checks with respect to the specification of the controls as well as to the use of alternative instruments. Column 1 simply repeats our baseline specification from table 4. Column 2 reports a first specification check, using an alternative specificiation of the socio-demographic controls. It differs from the baseline model in allowing for interaction effects between gender, age, and education. More precisely, it includes the gender-age-education distribution with four education categories and seven ten-year age categories. The resulting point estimates are again virtually idential with our baseline estimates. In column 3 we add canton-specific fixed effects to our baseline specification. This drives down the point estimate on the share of culturally different immigrants, which remains large and statistically significant, however.

\section{Table 5}

The last four columns of table 5 use the same specification of control variables, but they use alternative instruments. Specifically, column 4 uses the 1970 settlement pattern of immigrants

\footnotetext{
${ }^{16}$ We have also checked that the reduced form effects exist (and thus that the 2SLS estimates are not exclusively driven by a strong first-stage effect).
} 
at the community level. As expected, the point estimate is considerably smaller than in our baseline specification, with a point estimate of 0.343 and a robut t-value of 0.198 . Interestingly, the pattern of the different specifications is in line with our intutition that OLS estimates underestimate the true effect (the 2SLS estimates are larger than the corresponding OLS estimates, independent of the instrument used) and that, at the same time, the estimates based on alternative instruments bound the true effect of immigration on attitudes. Specifically, while our baseline estimates may overestimate the effect (due to a potential direct effect of the instrument), the estimates using the historical settlement pattern likely underestimate the true effect because of native outflows not explicitly taken into account by this identification strategy. In the fifth column we also use immigrants' historical settlement pattern as instrument, but we construct the instrument at the level of local labor markets instead of communities, thus combining in a way the logic of the two instruments. This yields an even larger, but also much less precise, point estimate on the share of culturally different immigrants of 5.795 (with a robust t-value of 3.344), while the estimate on the share of culturally similar immigrants remains statistically insignificant. We remain somewhat cautious regarding this specification, however, because one of the first-stage F-statistics turns out to be very small. The final two columns use instruments constructed at the cantonal level (note that the number of cantons is considerably smaller than the number of local labor markets), and they confirm our previous findings. Column 6 reports estimates that use cantonal immigrant shares as instruments and yields substantially larger estimates than our baseline specification. ${ }^{17}$ Finally, the last column instruments the communal immigrant shares with the cantonal immigrant shares in the year 1970. This yields a point estimate which is again close in size to the one from column 5 (again, however, one of the F-statistics is very small in this specification).

\section{Data issues}

Table 6 presents some additional robustness checks, which take up the most important data issues that have been brought up in previous sections. A first data issue is that there are different ways of merging the voting results with the census data, which are available only

\footnotetext{
${ }^{17}$ This could simply imply that some individuals' mobility is not restricted to a specific local labor market, with the consequence that even the 2SLS estimates may be downward biased. Using immigrant shares at the cantonal level as instrument sheds light on this issue because, compared to a local labor market, a canton encompasses a much wider area.
} 
every ten years. The second column thus first shows estimates that use data which have been aggregated by decade. While this massively reduces the number of observations, to less than $20 \%$ of the overall sample, the key estimates remain virtually unchanged.

\section{Table 6}

A potentially more important issue relates to the fact that most of the control variables (exept immigrant shares) have been imputed for the year 2010 due to the structural break in the collection of the data (as explained in footnote 9). For this reason, we exclude all socio-demographcic controls in column 3 (an alternative motivation for this specification acknowledges that part of these variables may be thought of as being endogenous as well). This yields a considerably smaller, but still significant and positive point estimate on the share of culturally different immigrants of 0.657 (with a robust t-value of 1.676). As an additional check in this respect, we also re-estimate our baseline specification excluding the data from 2010 altogether. As shown in column 4, this does not change the point estimate of the share of culturally different immigrants by much, but it yields a significant point estimates on the share of culturally similar immigrants of 0.389 , in contrast to our baseline estimates. Note, however, that this may also be due to time-varying coefficients (an issue that we tackle in more detail below).

Column 5 reports estimates using standardized values of anti-immigration votes as the dependent variable to take into account that, since the votes cover very different subjects, the cross-sectional variation in anti-immigration votes may differ across votes (remember that we do net out any differences in the mean values of attitudes across votes by including vote fixed-effects in all specifications). In part by construction, this yields a much larger point estimate than our baseline specification. Computing the corresponding semi-elasticity of antiimmigration votes with respect to the share of culturally different immigrants in terms of the standard deviation of the dependent variable, however, shows that this indeed yields an even stronger result. Our baseline specification implies a semi-elasticity of about $0.15(0.42)$ standard deviations for the share of culturally similar (different) immigrants, while column 5 yields corresponding semi-elasticities of about $0.24(0.67)$.

The last two columns of table 6 finally check the robustness of our main results with respect to the weighting scheme. We re-estimate our baseline specification without any weighting in 
column 6 , and we use a slightly alternative weighting scheme in the final column of table 6 . In the case of unweighted observations, we find that both the share of culturally different and the share of culturally similar immigrants have a positive impact on the share of anti-immigration votes. A similar result is shown in the final column, where the observations are weighted with the local native population instead of the local voting population. This specification may be understood as approximating the counterfactual situation of full voter turnout, assuming that there is no participation bias (an issue that we take up in more detail in section 6 below).

\section{Single-vote results}

Considering that the different votes cover widely varying topics, as evident from table 1 , it further appears necessary to examine whether the results also hold for single votes. This is done by simply re-running our baseline specification for each single vote. Results are depicted graphically in figure 3, with the vertical axis indicating the corresponding 2 SLS point estimate along with its $95 \%$ confidence interval, and the horizontal axis indicating the number of the vote, in chronological order. For the ease of comparison, the figure also shows the overall effect when pooling the votes together, corresponding to our baseline 2SLS estimates from table 4 .

Figure 3

As evident from panel (a), point estimates turn out positive for almost all single votes and they are statistically significantly different from zero in the majority of cases. Turning to panel (b), the single-vote results again confirm that there is no strong evidence of a relationship between voting results and the share of culturally similar immigrants, even though the share of culturally similar immigrants turns out positive in a few instances. Taken together, figure 3 suggests that our baseline estimates are robust and that the same pattern also holds for single votes (and thus for different points in time as well).

\section{Cultural classification of immigrants}

A final robustness check relates to the classification of immigrants into different cultural groups. In this context, a first thing to note is that there is a lot of heterogeneity in cultural values and beliefs within the group of immigrants defined as culturally different from natives. In fact, as mentioned in section 2 above, the latter group includes societies that differ only on 
the first value dimension (i.e. they place high emphasis on survival instead of self-expression values) as well as societies that differ on both dimensions (i.e. societies that further attach great importance to traditional rather than secular-rational values).

A first check thus aims to investigate whether the effect of the share of culturally different immigrants is driven by one of these two value dimensions. For this purpose we re-run the baseline model with three instead of two groups of immigrants: culturally similar immigrants, culturally different immigrants who differ only on one, and culturally different immigrants who differ on both dimensions. ${ }^{18}$ Column 2 of table 7 presents the resulting 2SLS estimates. Not surprisingly, the coefficient on the share of culturally similar immigrants remains small and statistically insignificant. More interestingly, note that the estimates appear to increase in the cultural distance between natives and immigrants: the point estimate on the share of immigrants different on both dimensions is more than twice as large as the estimated coefficient on the share of immigrants that differ only on one of the two dimensions (however, the two coefficients are estimated imprecisely, rendering them not statistictically different from each other).

Table 7

The remaining columns of table 7 show estimates that classify immigrants based on either the (dominant) language or dominant religion of their source country, instead of it's set of values and beliefs. Specifically, in column 3 we split immigrants based on the dominant language of their home country, distinguishing between immigrants from countries with a dominant language which is also a native language in Switzerland (i.e. German, French, or Italian) and all other immigrants. In column 4 we use a more restrictive version classification based on language, defining only those immigrants as culturally similar who speak a region's dominant language (e.g. German immigrants who reside in the German-speaking part of Switzerland). Both specifications yield estimates which are very close to our baseline estimates. The last column shows estimates that classify immigrants according to the dominant religion in their home country, where we define immigrants from predominantly protestant or catholic countries as culturally similar immigrants. Again, the resulting estimates turn out to be very similar to our baseline estimates.

\footnotetext{
${ }^{18}$ The first group is dominated by countries formerly under communist regimes, including immigrants from fromer Yugoslavia, while the second group contains regions from South Asia, Africa, as well as Latin America.
} 


\subsection{Heterogeneous effects}

Their robustness notwithstanding, our results remain somewhat ambiguous to this point because the two groups of immigrants may also differ from each other on dimensions other than their cultural values and beliefs. In a next step we thus try to shed some light on this issue by estimating several specifications that include interaction terms between the two immigrant shares and measures of either labor-market tightness or compositional amenities.

To this end we will distinguish between regions that differ in the level of tightness of their local labor market. ${ }^{19}$ In a first corresponding sample split we differentiate between regions that do, or do not, border a foreign country, the idea being that local labor markets which border a foreign country have tighter labor markets due to cross-country commuters. Alternatively, we use a dummy variable indicating the geographical remoteness of a local labor market to proxy for the slackness of a local labor market (assuming that labor markets are less tight in geographically remote areas). ${ }^{20}$ In a second and complementary step we also try to provide some direct evidence on the importance of compositional amenities among natives. There are limitations on what can be done with the census data, but we think that the share of children aged 15 or younger among natives withinin a community presents an interesting and direct measure of the importance of the ethnical composition of local neighborhoods, and especially schools, among natives.

Table 8

Table 8 shows the resulting estimates, with the first column repeating our baseline specification which includes no interaction terms at all. The second column shows estimates that include the interactions between the two immigrant shares and a dummy that takes on the value of one if a local labor market borders a foreign country and zero otherwise. Both interaction terms are positive and statistically significant, indicating that tighter labor market conditions lead to more intense attitudinal reactions among natives against both groups of immigrants. However, these estimates also imply that the difference between the two coefficients

\footnotetext{
${ }^{19}$ Note that any sample split along the borders of local labor markets is exogenous with respect to attitudes towards immigration if the key identifying assumption (i.e. no mobility of individuals across local labor markets motivated by ethnical concerns) holds true (see section 4.2 above).

${ }^{20}$ We first measure the remoteness of a community by the share of its area that is unproductive (i.e. is neither urbanized nor used for agriculture). We then define a given community as remote if this share is larger than $24.8 \%$ (which equals the 90th percentile of the corresponding distribution) and, consequently, a local labor market as remote if it contains at least one remote community.
} 
is not statistically different between border and non-border areas (the estimated difference equals 0.152 , with a robust standard error of 0.183$).{ }^{21}$ The fact that we observe a differential impact of the two groups of immgrants among both border and non-border areas suggests that the differential cannot be explained by an underlying difference in the labor-market effects of the two groups of immigrants. Column 3 shows the estimated interaction terms with our measure of the remoteness of a local labor market. In contrast to above, these estimates turn out to be statistically insignificant, but they still appear to be consistent with the results from the second column (i.e. both point estimates are negative, mirroring the result from the second column). As in column 2, there is no significant change in the difference between the two parameter estimates (estimated difference of -0.109 , with a robust standard error of 0.159). ${ }^{22}$ The fourth and final column of table 8 includes the interaction terms with the share of children below the age of 15 among the native population. In this case we find large and highly significant coefficients, with the interaction term between the share of young children and the share of culturally similar (different) immigrants being negative (positive). Combined, these estimates imply that the difference in the impact of culturally similar and culturally different immigrants, respectively, does significantly vary with the share of young children in a community (i.e. the difference between the two interaction terms is statistically significant as well). Thus natives' attitudes towards immigration appear to be especially sensitive to the share of culturally different immigrants in communities with large shares of children. This in turn suggests that compositional amenities, such as those derived from the cultural composition of schools, do play an important role in shaping natives' attitudes towards immigration (in line with previous results from Cascio and Lewis, 2012, inter alia).

\section{Voter turnout and external validity}

A potentially important issue which we have ignored so far is that voting is not compulsory in Switzerland anymore (with the exception of the canton of Schaffhausen, a case which is discussed in more detail below). Consequently, all findings presented so far are based on the

\footnotetext{
${ }^{21}$ The difference between $\widehat{\beta}^{d}$ and $\widehat{\beta}^{s}$ equals 0.948 in our baseline specification (with a robust standard error of 0.257 ). In column 2, the corresponding difference amounts to 1.187 (robust standard error of 0.332 ) for non-border areas and to 1.339 (robust standard error of 0.361) for border areas.

${ }^{22}$ The difference between $\widehat{\beta}^{d}$ and $\widehat{\beta}^{s}$ equals 0.934 (robust standard error of 0.265 ) for non-remote areas and 0.825 (robust standard error of 0.258 ) for remote areas.
} 
voting behavior of those individuals who actually decided to participate in a specific vote only. Given that voter turnout hovers around $51 \%$ in votes about immigration topics (cf. last column of table 1), and given that there is some evidence that this may be a selected group of individuals, the question arises of whether our results in part reflect participation bias or whether they extend to the non-voting native population as well. ${ }^{23}$ While this does not directly affect the validity of our empirical approach, participation bias may considerably restrict the external validity of our findings. We approach this important issue using three different empirical strategies.

\subsection{Stratifying communities by voter turnout}

Our first strategy is to re-estimate our baseline specification for subsamples of communities characterized by different voter turnout. Specifically, we divide our overall sample into 100 subsamples, each containing observations (i.e. municipality $\times$ vote cells) belonging to a particular percentile of the distribution of voter turnout. We then simply re-estimate our baseline specification within each single subsample. ${ }^{24}$

Figure 4

The resulting estimates are presented graphically in figure 4, with panel A (panel B) referring to the coefficient on the share of culturally different (similar) immigrants. In each figure, the vertical axis indicates the point estimates of the impact of the culture-specific immigrant share (in percentage points), while the horizontal axis depicts the corresponding turnout percentile, numbered from 1 to $100 .^{25}$ Consider the effect of culturally different immigrants first.

\footnotetext{
${ }^{23}$ Interestingly, voter turnout tends to be higher in votes about immigration issues than otherwise. Moreover, according to Miguet (2008), who uses post-vote datasets for two of the votes from table 1 (vote number 355 and 467), participation is significantly more likely for highly educated and married persons, and for individuals with views at the political extreme. Similar results are reported by Krishnakumar and Müller (2012), who study vote number 467 as well. Note, however, that these two studies focus on single votes only, while we pool results across 27 different votes. Another issue is that the post-poll data are subject to considerable non-response as well.

${ }^{24}$ One way to motivate such an analysis is that we expect that the impact of immigration applies equally to all individuals if no unobserved characteristic exists that simultaneously influences anti-immigration attitudes and the probability of voting. Conversely, if there is a systematic relationship between participation decisions and attitudes towards immigration that observed individual characteristics do not explain, one would expect to find a correlation between the size of the estimated effects and the voter turnout.

${ }^{25}$ The observed variation in voter turnout across communities and over time is quite large. The median turnout in our sample equals $50.5 \%$, the 5 th and the 95 th percentile correspond, respectively, to a voter turnout of $30.1 \%$ and $81.5 \%$.
} 
Interestingly, the results do not provide any indication of a systematic relationship between the size of the parameter estimates and the voter turnout (unless perhaps for observations with very high voter turnout). For each turnout subsample, 2SLS estimates are statistically significant and vary between 0.75 and 2.5 - with exception of the upper turnout decile. For those observations, the estimated effect is considerably larger (point estimate of up to 4.75), but so is the associated standard error. The corresponding estimates for the share of culturally similar immigrants again suggest no causal effect from the share of culturally similar immigrants on natives' attitudes towards immigration.

\subsection{Close votes}

An alternative strategy starts from the observation that we expect that voter turnout partially depends on the specific subject of a vote (one important characteristic of a vote in this regard is it's anticipated impact in the case of acceptance or rejection, respectively). ${ }^{26}$ Thus one way to study whether the estimated impact of local immigrant shares varies with turnout is to check whether the estimated parameters vary across votes, depending on how controversial, and thus how mobilizing, a specific vote has been. We use two slightly different measures of the closeness of a vote, which are both associated with a higher voter turnout (as shown at the bottom of table 9). Our first measure focuses on the overall approval rate of a vote (as shown in column 7 of table 9), and we define those votes with an overall approval between $45 \%$ and $55 \%$ as close votes. Alternatively, our second measure defines those votes as close where more than $30 \%$ of all communities had an approval rate between $45 \%$ and $55 \%$.

\section{Table 9}

Columns 2 and 3 of table 9 show the resulting estimates for the two alternative definitions of a close vote. In both cases, and consistent with the estimates from previous figure 4, the point estimate on the share of culturally different immigrants gets slightly larger than in the overall sample (with a point estimate of 1.441 and 1.354, respectively, in the sample of close votes versus a point estimate of 1.153 in the overall sample), but the difference with the baseline estimates is, once again, not significantly different from zero. Consistent with the results from

\footnotetext{
${ }^{26}$ Typically, there are several votes taking place at the same time, often covering very diverse issues. As a consequence, voter turnout may thus also be influenced by the specific combination of votes taking place at the same time.
} 
above, these estimates provide no clear evidence that the effect of immigration on attitudes is influenced by voter turnout.

\subsection{Mandatory voting in the canton of Schaffhausen}

Yet another, and presumably the most stringent, strategy relies on the fact that voting is formally still mandatory in the canton of Schaffhausen, located in the northeast of the country. ${ }^{27}$ In our third strategy, we restrict the sample to communities from the canton of Schaffhausen and its two neighboring cantons, Thurgau and Zurich, and then instrument voter turnout with a dummy for mandatory voting (which is simply equivalent to a dummy variable taking on the value of one for all communities belonging to the canton of Schaffhausen and zero otherwise).$^{28}$ The last three columns of table 9 report estimates which are based on this specific subsample of observations.

First, column 4 simply replicates our baseline specification, using the restricted sample of communites from the three cantons only. The estimates of the two immigrant shares turn out very similar as when using the overall sample (compare with column 1). Including voter turnout as an exogenous regressor, as done in column 5, yields a positive and statistically significant estimate on voter turnout, which whould imply that a higher turnout is associated with more intense anti-immigration votes (which is consistent with the evidence cited in footenote 23). However, turnout can hardly be considered exogenous, and the last column of table 9 shows that the effect of turnout on natives' anti-immigration votes becomes very small and statistically insignificant when we instrument for it using the dummy variable indicating mandatory voting (note that the instrument for voter turnout is very strong, with a large robust F-value of about $124)$.

\subsection{Summing up the evidence on participation bias and external validity}

Taken together, we draw two main conclusions from these findings on voter turnout and potential participation bias. First, all three strategies suggest that higher voter turnout is, if

\footnotetext{
${ }^{27}$ Interestingly, voter turnout in Schaffhausen is consistently and significantly higher than in all other parts of Switzerland even though the monetary sanction for non-participation is of symbolic nature at best (there is a fine of three Swiss Francs, roughly equivalent to about $2.5 €$, for each vote missed). See Schwegler (2009) for interesting details about mandatory voting in the canton of Schaffhausen and in Switzerland in general.

${ }^{28}$ We get very similar estimates when we use a subsample containing all communities belonging the NUTS-2 region to which the canton of Schaffhausen belongs to (Eastern Switzerland).
} 
anything, associated with slightly more intense anti-immigration votes. This finding is consistent with previous studies focusing specifically on voter turnout in Switzerland for selected votes (Krishnakumar and Müller, 2012; Miguet, 2008). More importantly, however, we also find that our results are only marginally, if at all, influenced by particpation bias, and that the qualitative pattern does not depend on selective participation in the corresponding votes. This is important as it greatly strenghtens the external validty of our results. Of course, that is not to say that the results would necessarily still be the same if voter turnout was $100 \%$, but our results do show that the results do not change in a substantive way even for reasonably large changes in voter turnout.

\section{$7 \quad$ Right-wing votes}

We finally look at the relation between immigration and right-wing votes, and compare the resulting estimates with those we obtained for natives' attitudes towards immigration. Similar to many other European countries, Switzerland has recently experienced a distinct rise in the vote share in favor of the Swiss People's Party ("Schweizerische Volkspartei", SVP for short), a political party known for its fierce anti-immigration program (McGann and Kitschelt, 2005). ${ }^{29}$ This last section aims at investigating whether the local presence of immigrants with different cultural values and beliefs is a similarly important determinant of the share of right-wing votes as it is of the share of anti-immigration votes. Moreover, a comparison with our earlier results on the impact of local immigrant shares on natives' anti-immigration votes may also help to clarify the practical importance of policy bundling mentioned in the introduction (cf. footnote 2). This, in turn, may clarify the external validity of estimates from studies which relate local immigrant shares with votes in favor of right-wing parties which have been mentioned in the introduction (and whose estimates are potentially blurred by the issue of policy bundling). ${ }^{30}$ In fact, we are not aware of any study that has yet provided such a direct comparison between the impact of immigration on attitudes on the one hand and on vote shares for political parties

\footnotetext{
${ }^{29}$ From 1970 until 1991, vote shares in favor of the SVP in elections of the national parliament equalled about $10 \%$. In subsequent years, however, the party gained more and more support and reached its highest share of votes in 2007 with about $27 \%$. This corresponds to an increase of almost two hundred percent over a period of 16 years only. The rapid rise of the SVP levelled off in the 2011 elections, when the party even had to record a slight decrease compared to the previous election period.

${ }^{30}$ Obviously, results based on election outcomes are potentially subject to participation bias as well, as discussed in section 6 .
} 
on the other hand.

To explore this question empirically, we additionally draw on results from the elections of the members of the Swiss National Council ("Nationalrat") within our sample period. ${ }^{31}$ Election outcomes are also available at the community level, and we can thus apply the same estimation strategy as before, using the vote shares in favor of the SVP as the dependent variable. ${ }^{32}$

\section{Table 10}

Table 10 presents the corresponding estimates. As before, the first column simply replicates our baseline estimates from table 4. The next column shows the results from estimating our baseline specification on the national-elections sample, i.e. the same sample that is available in the case of the election results. ${ }^{33}$ The final column shows the estimated impact of the culturespecific immigrant shares on the community-leve vote shares in favor of the Swiss People's Party. For the ease of comparison, the table also shows approximate elasticites, evaluated at mean values, in curly brackets.

Comparing the estimates for anti-immigration votes with the corresponding estimates for vote shares in favor of the SVP, first note that the general pattern of estimates is basically the same. We find a small and statistically insignificant effect for the share of culturally similar immigrants and a large and statistically significant effect for the share of culturally different immigrants. Also, the instruments remain strong for the two endogenous variables. The most interesting result from this comparison however is that vote shares turn out to be far more elastic with respect to the share of culturally different immigrants than natives' antiimmigration attitudes themselves. Specifically, the estimates from table 10 imply that the elasticity of votes in favor of the SVP (approximate elasticity of 0.309 if evaluated at mean values) is two to three times as large as the corresponding elasiticy of anti-immigration votes

\footnotetext{
${ }^{31}$ As the parliamentary elections take place every four years, the election years do not perfectly coincide with the census years. We therefore merge the 1971 election results to the 1970 census, the 1979 election results to the 1980 census, the 1991 election results to the 1990 census, the 1999 election results to the 2000 census and finally, the 2011 election results to the 2010 census.

${ }^{32}$ The cross-section of communities is somewhat smaller than in the main part of the empirical analysis because a slightly different version of the municipality boundaries that is used in order to record election results. As a consequence, 24 out of the total of 2,544 municipalities cannot be merged to the census data when working with the election results.

${ }^{33}$ Note that we get similar results when the estimation sample is restricted to those observations that can also be used to analyze vote shares in favor of the SVP.
} 
(elasticity of 0.141 and 0.102 , respectively). Thus, at least in the case of Switzerland, estimates based on right-wing shares would overestimate the effect of immigration on natives' attitudes to immigration. While the large discrepancy between the two elasticities may be specific to the context of our study, this result clearly indicates potential interpretational problems when exclusively using right-wing votes as a measure for natives' attitudes.

It thus appears that the Swiss People's Party has been very successful in disproportionately gaining vote shares from changes in natives' attitudes towards immigration which have actually been caused by immigrant inflows. This, in turn, suggests that the other political parties have been largely unwilling or unable to lead a serious discussion about the pros and cons of immigration.

\section{Conclusions}

In this paper, we combine outcomes of national votes about immigration policies in Switzerland between 1970 and 2010 with data from the Swiss census to estimate the causal effect of local immigrant shares on natives' attitudes towards immigration. We focus on understanding how this relationship is affected by the level of dissimilarity in cultural values and beliefs between natives and immigrants. Moreover, to take the potential endogeneity of locational decisions into account, we instrument the immigrant share within a community with the immigrant share of the local labor market a community belongs to.

We find that it is not so much the overall immigrant share, but mainly the presence of immigrants with a different cultural background that affects the voting behavior of Swiss citizens. Specifically, the local share of culturally different immigrants turns out to be a significant and sizable determinant of the share of anti-immigration votes while, in contrast, the presence of culturally similar immigrants does not seem to affect natives' voting behavior at all. Our preferred estimates imply that a one percentage point increase in the local share of culturally different immigrants results in a 1.15 percentage point increase in anti-immigration votes in an average national vote about immigration. This estimate implies an approximate elasticity of natives' anti-immigration attitudes with respect to the share of culturally different immigrants of about 0.14. This finding turns out to be robust to a variety of robustness checks, including the use of alternative instruments and the use of alternative classifications of immi- 
grants. Moreover, an additional analysis of voter turnout and the potential of participation bias suggests that our main results are only weakly, if at all, influenced by participation bias, strengthening the external validity of our estimates. Finally, analyzing vote shares in favor of the right-wing Swiss People's Party at national elections over the same time period reveals that the share of right-wing votes is even more elastic with respect to the share of culturally different immigrants than natives' attitudes to immigration (with an estimated elasticity of about 0.31$)$.

As we have emphasized throughout the paper, we think that the most plausible explanation for the large positive effect of culturally different immigrants on natives' anti-immigration attitudes, and the share of culturally similar immigrants being mostly insignifiant at the same time, relates to cultural concerns among native residents. More specifically, part of the native population appears to perceive culturally different immigrants as threatening their national identity, i.e. their culture, their language, religion, and their way of life in general. However, since cultural values and beliefs are not the only difference between the two groups of immigrants, we can not rule out that other mechanisms (such as differential labor-market impacts of the two groups of immigrants) are also important. We have, for this reason, shown some additional evidence which appears very much in line with our argument that the differential impact of the two groups of immigrants on natives' attitudes to immigration is, to a large extent, driven by concerns about compositional amenities derived from, for example, the cultural composition of childrens' peers at school.

We believe that our findings have important implications for the ongoing debate about immigration and labor-market policy in Switzerland, and far beyond. Indeed, the evidence discussed in Akerlof and Kranton $(2000,2010)$ suggests that concerns about identity are pervasive and thus that similar mechanisms are likely at work in other immigration countries. Similarily, the survey data reported in Card et al. (2012) show that Switzerland is by no means a special case with respect to attitudes towards immigration when compared with other European countries. We thus believe that our findings have important implications for immigration and labor-market policy in the typical European immigration country. ${ }^{34}$ Taken together, our results suggest that there may be an emerging antagonism between (parts of)

\footnotetext{
${ }^{34}$ Indeed, on February 9, 2014, a popular initiative "Against mass immigration", demanding direct restrictions on the level of immigration, was accepted by the Swiss electorate (though only by a tiny margin of $50.3 \%$ of the votes in favor of the initiative).
} 
labor markets getting continously more globalized on the one hand, and attitudinal responses of natives in immigration host countries getting more hostile towards immigration, especially from culturally different countries. We would also argue that natives' discontent with immigration runs much deeper than is usually thought by economists and by policy makers alike. This suggests that the almost exclusive focus on the potential labor market effects of immigration in most public debates about immigration is somewhat misguided, as it misses important other aspects of immigration that are in principle independent of any economic impacts of immigration. Most importantly, perhaps, our results thus point out that there might be, in the end, political-economic limitations on the level and eventually the composition of immigration, rather than restrictions due to a limited capacity of labor markets to integrate even large inflows of immigrants economically. 


\section{References}

Akerlof, G. A. and Kranton, R. E. (2000). Economics and identity. Quarterly Journal of Economics, 115(3), 715-753.

Akerlof, G. A. and Kranton, R. E. (2010). Identity economics: How our identities shape our work, wages, and well-being. Princeton University Press.

Altonji, J. G. and Card, D. (1991). The effects of immigration on the labor market outcomes of less-skilled natives. In J. M. Abowd and R. B. Freeman, editors, Immigration, trade and the labor market, pages 201-234. University of Chicago Press.

Angrist, J. and Krueger, A. (1994). Why do World War II veterans earn more than nonveterans? Journal of Labor Economics, 12(1), 74-97.

Barone, G., D'Ignazio, A., de Blasio, G., and Naticchioni, P. (2014). Mr. Rossi, Mr. Hu and the politics. The role of immigration in shaping natives' political preferences. IZA Discussion Paper No. 8228.

Benz, M. and Stutzer, A. (2004). Are voters better informed when they have a larger say in politics? Evidence for the European Union and Switzerland. Public Choice, 119(1-2), $31-59$.

Bertrand, M. and Mullainathan, S. (2001). Do people mean what they say? Implications for subjective survey data. American Economic Review, 91(2), 67-72.

Bertrand, M., Duflo, E., and Mullainathan, S. (2004). How much should we trust differencesin-differences estimates? Quarterly Journal of Economics, 119(1), 249-275.

Card, D. (2001). Immigrant Inflows, Native Outflows, and the Local Labor Market Impacts of Higher Immigration. Journal of Labor Economics, 19(1), 22-64.

Card, D., Mas, A., and Rothstein, J. (2008). Tipping and the Dynamics of Segregation. Quarterly Journal of Economics, 123(1), 177-218.

Card, D., Dustmann, C., and Preston, I. (2012). Immigration, wages, and compositional amenities. Journal of the European Economic Association, 10(1), 78-119.

Cascio, E. U. and Lewis, E. G. (2012). Cracks in the Melting Pot: Immigration, School Choice, and Segregation. American Economic Journal: Economic Policy, 4(3), 91-117.

Casey, T. and Dustmann, C. (2010). Immigrants' identity, economic outcomes and the transmission of identity across generations. Economic Journal, 120(542), F31-F51.

Damm, A. P. (2009). Ethnic Enclaves and Immigrant Labor Market Outcomes: QuasiExperimental Evidence. Journal of Labor Economics, 27(2), 281-314.

Dustmann, C. and Preston, I. (2001). Attitudes to ethnic minorities, ethnic context and location decisions. Economic Journal, 111(470), 353-373.

Dustmann, C. and Preston, I. (2006). Is immigration good or bad for the economy? Analysis of attitudinal responses. Research in Labor Economics, 24, 3-34.

Dustmann, C. and Preston, I. (2007). Racial and economic factors in attitudes to immigration. The B.E. Journal of Economic Analysis \& Policy, 7(1), 62. 
Fernández, R. and Fogli, A. (2006). Fertility: The role of culture and family experience. Journal of the European Economic Association, 4(2-3), 552-561.

Gerdes, C. and Wadensjö, E. (2008). The impact of immigration on election outcomes in Danish municipalities. IZA Discussion Paper No. 3586.

Gross, D. (2006). Immigration policy and foreign population in Switzerland. Technical report, The World Bank.

Gross, D. M. (2012). Free Mobility with the EU and Immigration of North American Brains to Switzerland: What Consequences? Swiss Journal of Economics and Statistics, 148(4), $497-530$.

Hainmueller, J. and Hiscox, M. (2007). Educated preferences: Explaining attitudes toward immigration in Europe. International Organization, 61(02), 399-442.

Hainmueller, J. and Hiscox, M. (2010). Attitudes toward highly skilled and low-skilled immigration: Evidence from a survey experiment. American Political Science Review, 104(1), $61-84$.

Halla, M., Wagner, A., and Zweimüller, J. (2012). Does Immigration into Their Neighborhoods Incline Voters Toward the Extreme Right? The Case of the Freedom Party of Austria. IZA Discussion Paper No. 6575.

Harmon, N. A. (2012). Immigration, ethnic diversity and political outcomes: evidence from Denmark. Working Paper No. 569, Princeton University, Industrial Relations Section.

Hugo, G. (2005). Migrants in society: diversity and cohesion. Global Commission on International Migration Geneva.

Inglehart, R. and Baker, W. (2000). Modernization, cultural change, and the persistence of traditional values. American Sociological Review, 65(1), 19-51.

Krishnakumar, J. and Müller, T. (2012). The political economy of immigration in a direct democracy: The case of Switzerland. European Economic Review, 56(2), 174-189.

Lee, W. and Roemer, J. E. (2006). Racism and redistribution in the United States: A solution to the problem of American exceptionalism. Journal of Public Economics, 90(6), 1027-1052.

Li, Q. (2014). Ethnic diversity and neighborhood house prices. Regional Science and Urban Economics, 48, 21-38.

Mayda, A. (2006). Who is against immigration? A cross-country investigation of individual attitudes toward immigrants. Review of Economics and Statistics, 88(3), 510-530.

McGann, A. J. and Kitschelt, H. (2005). The Radical Right in The Alps Evolution of Support for the Swiss SVP and Austrian FPÖ. Party Politics, 11(2), 147-171.

Mendez, I. and Cutillas, I. M. (2014). Has immigration affected Spanish presidential elections results? Journal of Population Economics, 27(1), 135-171.

Miguet, F. (2008). Voting about immigration policy: What does the Swiss experience tell us? European Journal of Political Economy, 24(3), 628-641.

Moulton, B. (1990). An illustration of a pitfall in estimating the effects of aggregate variables on micro unit. Review of Economics and Statistics, 72(2), 334-38. 
Müller, T. and Tai, S. (2010). Individual attitudes towards migration: a reexamination of the evidence. Mimeo, University of Geneva.

O'Connell, M. (2011). How do high-skilled natives view high-skilled immigrants? a test of trade theory predictions. European Journal of Political Economy, 27(2), 230-240.

OECD (2013). International Migration Outlook 2013. Technical report, OECD Publishing.

Otto, A. H. and Steinhardt, M. F. (2014). Immigration and Election Outcomes-Evidence from City Districts in Hamburg. Regional Science and Urban Economics, 45, 67-69.

Quillian, L. (1995). Prejudice as a response to perceived group threat: Population composition and anti-immigrant and racial prejudice in Europe. American Sociological Review, 60(4), $586-611$.

Saiz, A. and Wachter, S. (2011). Immigration and the neighborhood. American Economic Journal: Economic Policy, 3(2), 169-188.

Scheve, K. and Slaughter, M. (2001). Labor market competition and individual preferences over immigration policy. Review of Economics and Statistics, 83(1), 133-145.

Schneider, S. (2008). Anti-immigrant attitudes in Europe: Outgroup size and perceived ethnic threat. European Sociological Review, 24(1), 53-67.

Schuler, M., Dessemontet, P., and Joye, D. (2005). Eidgenössische Volkszählung 2000: Die Raumgliederungen der Schweiz. Neuchâtel: Bundesamt für Statistik.

Schwegler, E. (2009). Motivstrukturen unter Stimmzwang. Working Paper No. 42, Center for Comparative and International Studies (ETH Zurich and University of Zurich).

Semyonov, M., Raijman, R., and Gorodzeisky, A. (2006). The rise of anti-foreigner sentiment in European societies, 1988-2000. American Sociological Review, 71(3), 426-449.

Staiger, D. and Stock, J. (1997). Instrumental variables regression with weak instruments. Econometrica, 65(3), 557-586.

Tolbert, C. and Hero, R. (1996). Race/ethnicity and direct democracy: An analysis of California's illegal immigration initiative. Journal of Politics, 58(3), 806-818.

Wong, M. (2013). Estimating Ethnic Preferences Using Ethnic Housing Quotas in Singapore. Review of Economic Studies, 80, 1178-1214. 


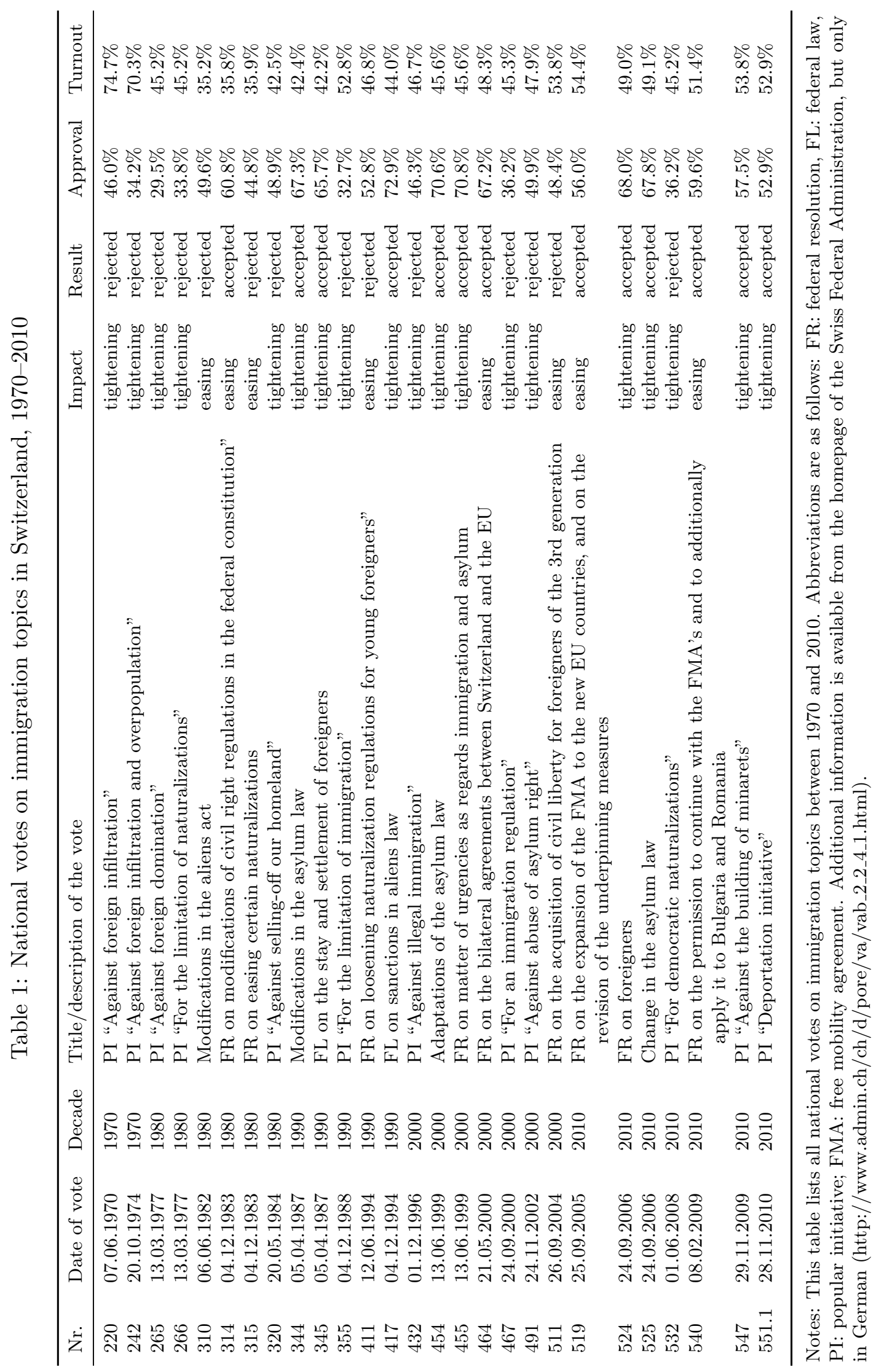


Table 2: Immigrant heterogeneity and density, 1970-2010

\begin{tabular}{|c|c|c|c|c|c|}
\hline & 1970 & 1980 & 1990 & 2000 & 2010 \\
\hline \multicolumn{6}{|c|}{ Panel A: Distribution of immigrants by country/region of origin } \\
\hline \multicolumn{6}{|l|}{ Europe } \\
\hline Austria & 4.14 & 3.40 & 2.42 & 2.00 & 2.10 \\
\hline Czechia and Slovakia & 1.20 & 1.52 & 0.50 & 0.38 & 0.64 \\
\hline Former Yugoslavia & 2.31 & 6.45 & 13.87 & 24.23 & 17.79 \\
\hline France & 5.17 & 5.03 & 4.23 & 4.19 & 5.42 \\
\hline Germany & 10.95 & 9.30 & 6.92 & 7.51 & 14.91 \\
\hline Hungary & 1.07 & 0.68 & 0.39 & 0.25 & 0.37 \\
\hline Italy & 54.06 & 44.34 & 30.77 & 21.54 & 16.26 \\
\hline Netherlands & 1.00 & 1.07 & 0.98 & 0.98 & 1.09 \\
\hline Portugal & 0.34 & 2.00 & 8.86 & 9.52 & 12.04 \\
\hline Spain & 11.23 & 11.38 & 9.97 & 5.65 & 3.63 \\
\hline Turkey & 1.13 & 4.09 & 6.56 & 5.57 & 4.07 \\
\hline UK & 1.37 & 1.63 & 1.44 & 1.49 & 2.11 \\
\hline Rest of Europe & 2.54 & 3.29 & 3.44 & 3.53 & 4.79 \\
\hline \multicolumn{6}{|l|}{ Rest of the World } \\
\hline Africa & 0.48 & 1.17 & 1.99 & 3.34 & 4.05 \\
\hline Asia and Oceania & 0.86 & 2.48 & 5.14 & 6.36 & 6.50 \\
\hline Asia & 0.76 & 2.33 & 5.00 & 6.16 & 6.27 \\
\hline North America & 1.32 & 1.20 & 1.14 & 1.28 & 1.45 \\
\hline South America & 0.39 & 0.96 & 1.30 & 2.14 & 2.77 \\
\hline \multicolumn{6}{|c|}{ Panel B: Overall and culture-specific immigrant shares } \\
\hline Overall immigrant share & 17.24 & 14.86 & 18.13 & 20.53 & 22.47 \\
\hline Share of culturally similar immigrants & 15.81 & 12.15 & 12.50 & 11.54 & 13.76 \\
\hline Share of culturally different immigrants & 1.43 & 2.71 & 5.63 & 8.99 & 8.72 \\
\hline
\end{tabular}

Notes: Panel A shows the distribution of immigrants across their country/region of origin (i.e. the numbers add up to $100 \%$ within each decade, besides potential rounding error). Panel B shows the overall immigrant share (i.e. the total number of immigrants as a fraction of the overall resident population) as well as the shares of culturally similar and culturally different immigrants (as defined in section 2) and the percentage share of culturally different immigrants among all immigrants. 


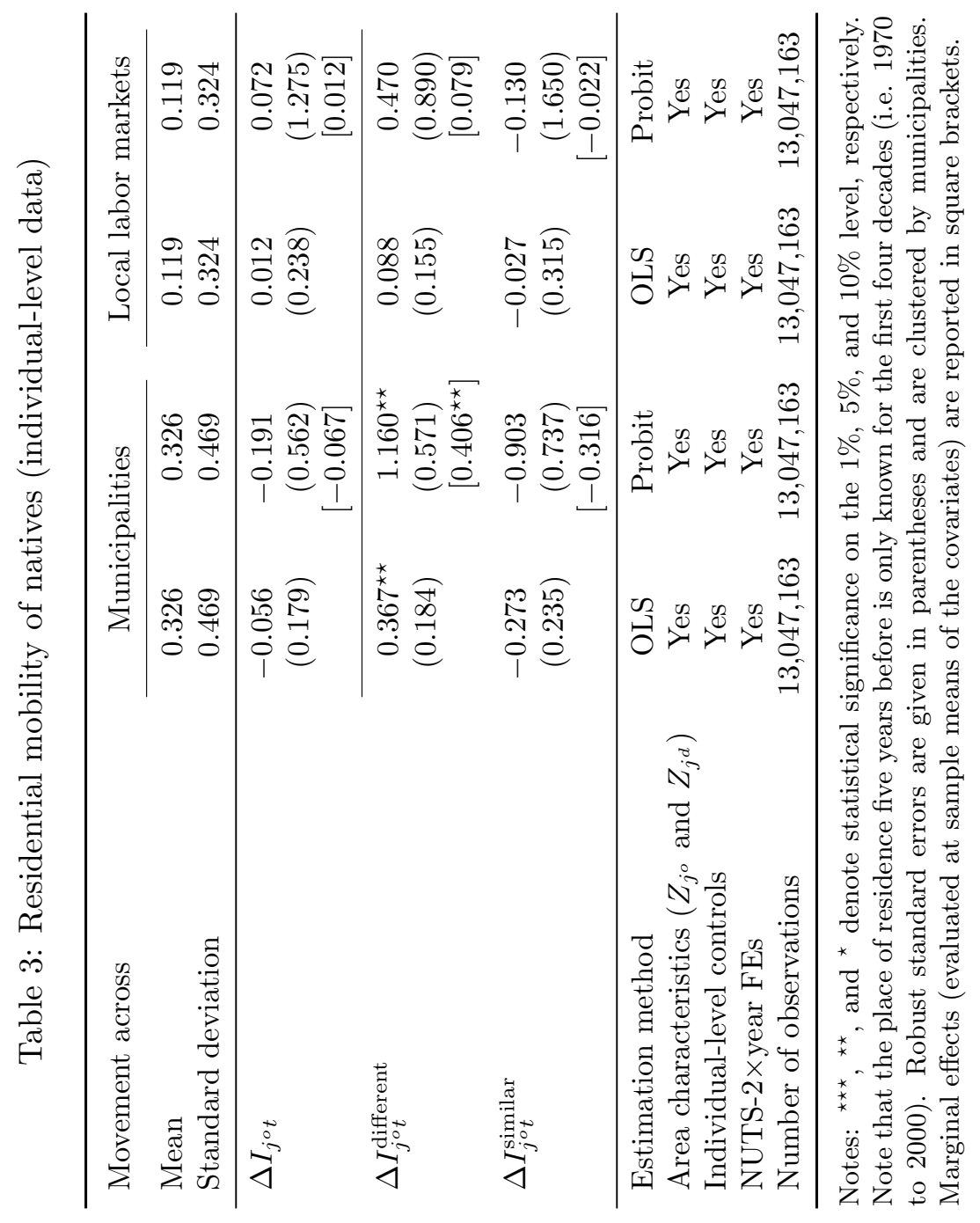




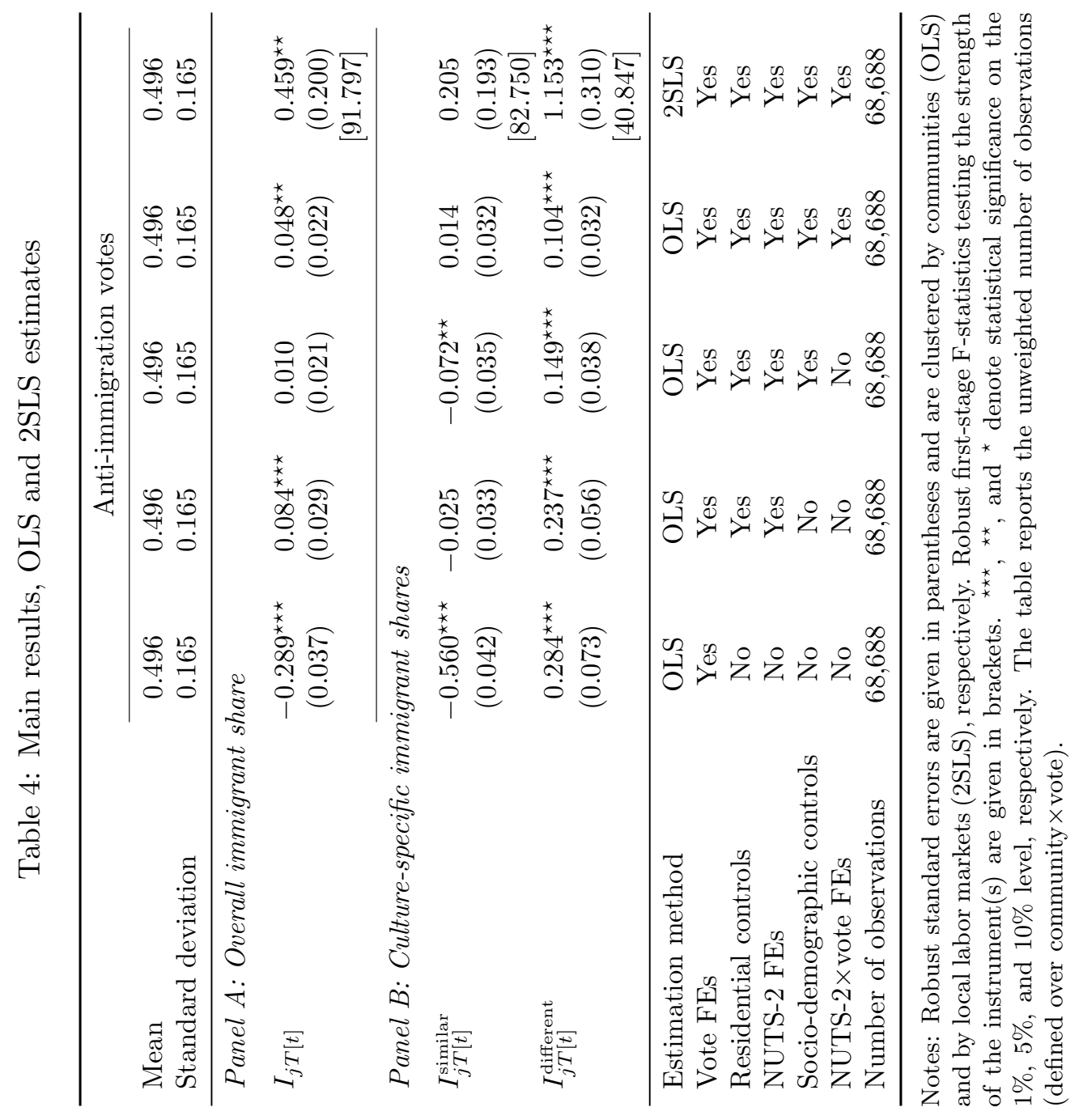




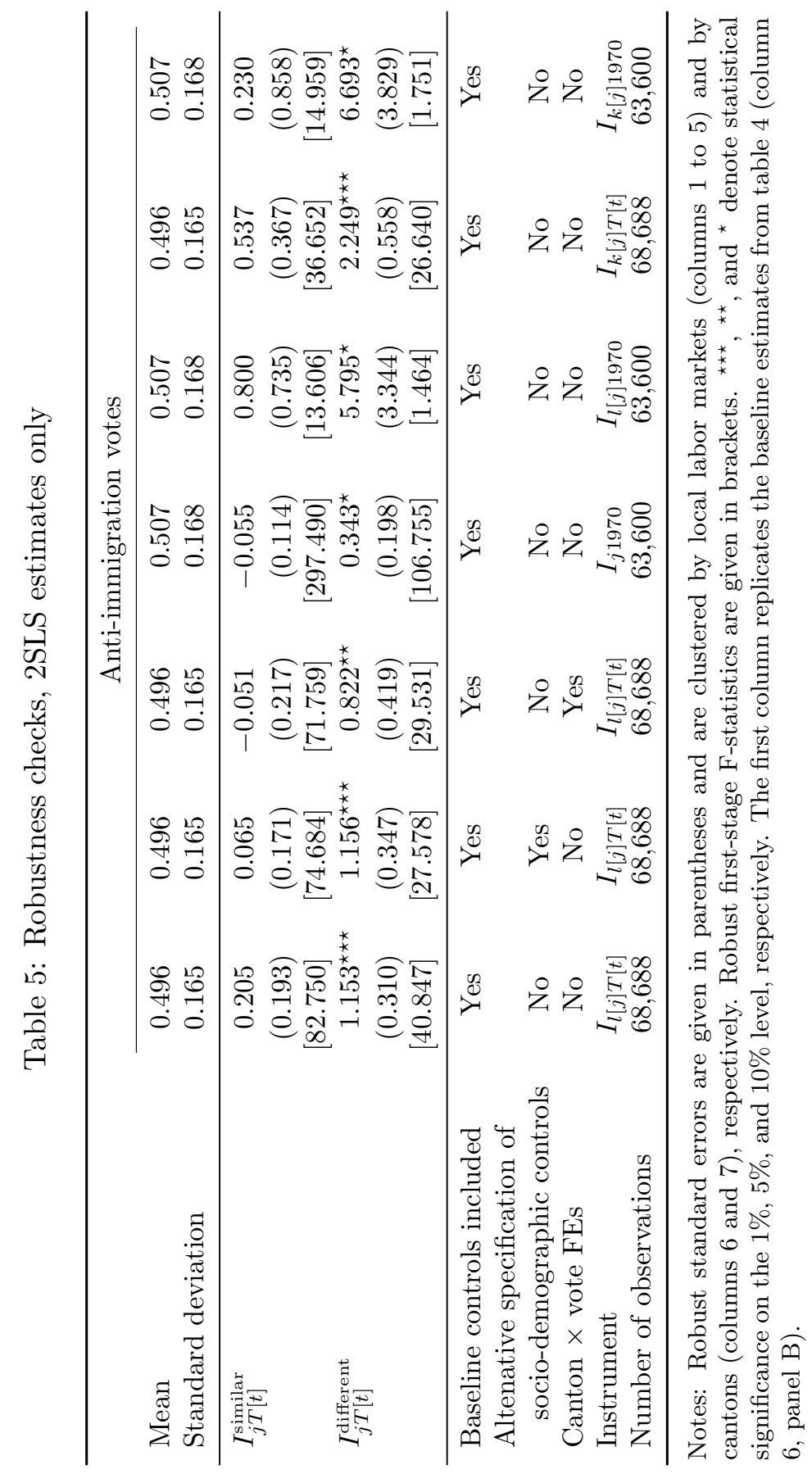




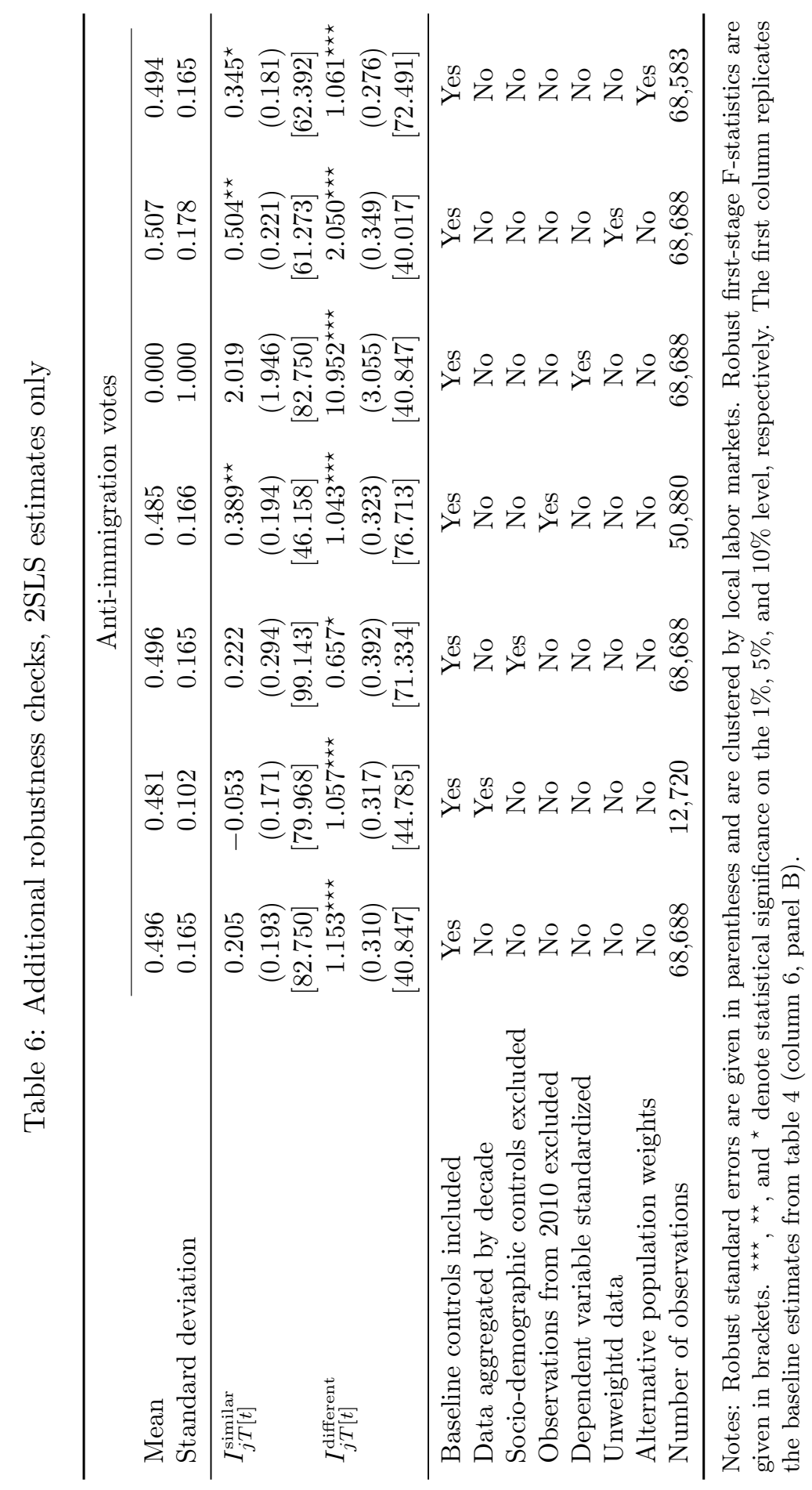




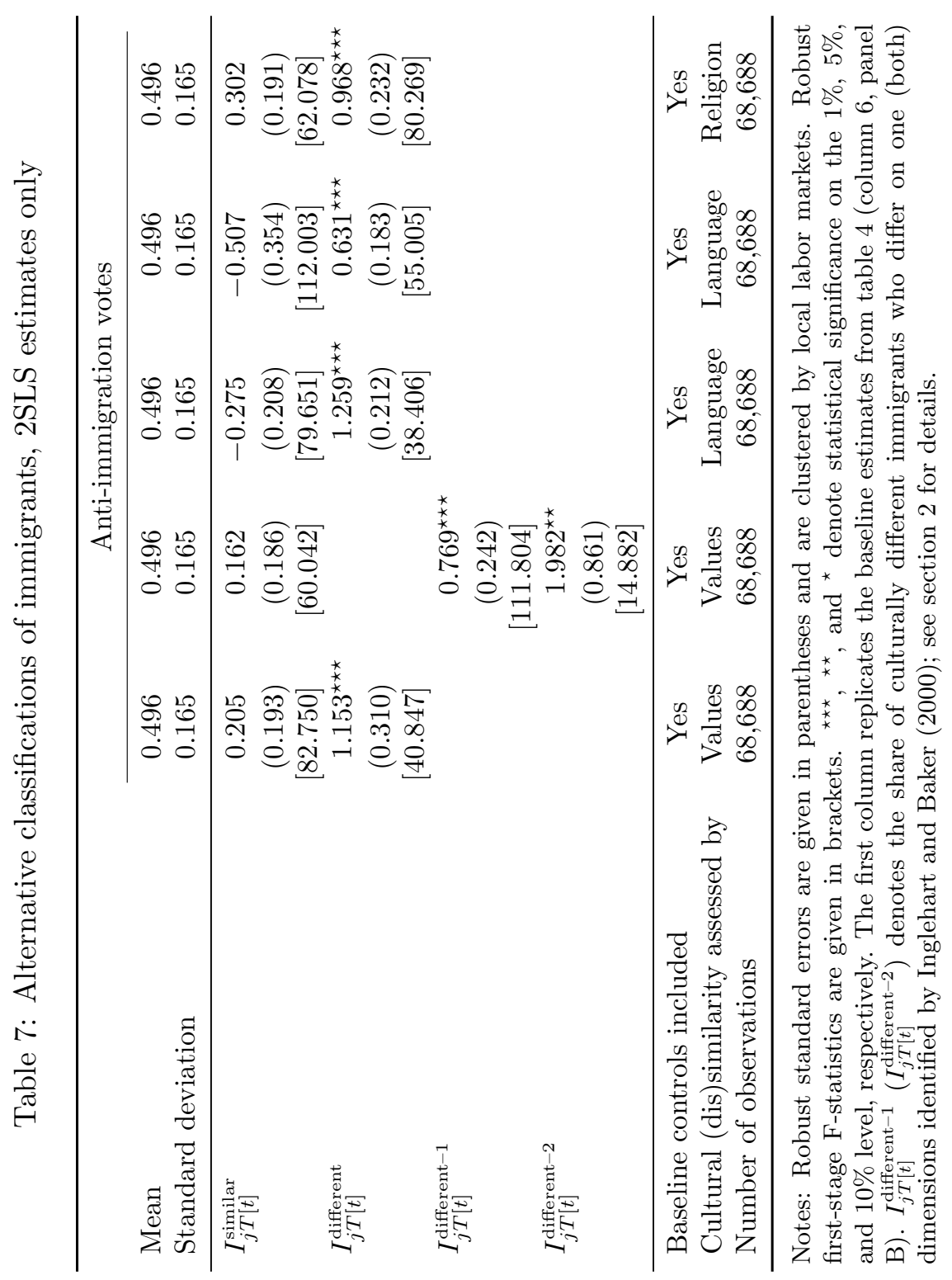


Table 8: Heterogeneous effects, 2SLS estimates only

\begin{tabular}{|c|c|c|c|c|}
\hline \multirow{3}{*}{$\begin{array}{l}\text { Mean } \\
\text { Standard deviation }\end{array}$} & \multicolumn{4}{|c|}{ Anti-immigration votes } \\
\hline & 0.496 & 0.496 & 0.496 & 0.496 \\
\hline & 0.165 & 0.165 & 0.165 & 0.165 \\
\hline \multirow[t]{3}{*}{$I_{j T[t]}^{\text {similar }}$} & 0.205 & 0.157 & 0.245 & 0.174 \\
\hline & $(0.193)$ & $(0.210)$ & $(0.217)$ & $(0.158)$ \\
\hline & {$[82.750]$} & {$[45.603]$} & {$[47.746]$} & {$[49.068]$} \\
\hline \multirow{3}{*}{$I_{j T[t]}^{\text {different }}$} & $1.153^{\star \star \star}$ & $1.345^{\star \star \star}$ & $1.178^{\star \star \star}$ & $1.747^{\star \star \star}$ \\
\hline & $(0.310)$ & $(0.329)$ & $(0.338)$ & $(0.273)$ \\
\hline & {$[40.847]$} & {$[19.806]$} & {$[35.741]$} & {$[19.833]$} \\
\hline \multirow[t]{3}{*}{$I_{j T[t]}^{\text {similar }} \times$ border $_{l[j] T[t]}$} & & $0.363^{\star \star \star}$ & & \\
\hline & & $(0.111)$ & & \\
\hline & & [196.083] & & \\
\hline \multirow{3}{*}{$I_{j T[t]}^{\text {different }} \times \operatorname{border}_{l[j] T[t]}$} & & $0.515^{\star \star \star}$ & & \\
\hline & & $(0.184)$ & & \\
\hline & & {$[232.741]$} & & \\
\hline \multirow{3}{*}{$I_{j T[t]}^{\text {similar }} \times \operatorname{remote}_{l[j] T[t]}$} & & & -0.094 & \\
\hline & & & $(0.114)$ & \\
\hline & & & [690.168] & \\
\hline \multirow{3}{*}{$I_{j T[t]}^{\text {different }} \times$ remote $_{l[j] T[t]}$} & & & -0.203 & \\
\hline & & & $(0.186)$ & \\
\hline & & & {$[311.809]$} & \\
\hline \multirow{3}{*}{$I_{j T[t]}^{\text {similar }} \times \operatorname{age}_{j T[t]}^{15}$} & & & & $-2.769^{\star \star \star}$ \\
\hline & & & & $(0.766)$ \\
\hline & & & & {$[45.221]$} \\
\hline \multirow{3}{*}{$I_{j T[t]}^{\text {different }} \times \operatorname{age}_{j T[t]}^{15}$} & & & & $10.212^{\star \star \star}$ \\
\hline & & & & $(1.696)$ \\
\hline & & & & {$[40.663]$} \\
\hline Baseline controls & Yes & Yes & Yes & Yes \\
\hline Number of observations & 68,688 & 68,688 & 68,688 & 68,688 \\
\hline
\end{tabular}

Notes: Robust standard errors are given in parentheses and are clustered by local labor markets. Robust first-stage F-statistics are given in brackets. ${ }^{\star \star \star}$, ${ }^{\star \star}$, and ${ }^{\star}$ denote statistical significance on the $1 \%, 5 \%$, and $10 \%$ level, respectively. The share of children below age 15 among natives, $\operatorname{age}_{j T[t]}^{15}$, is de-meaned such that the main effects of $I_{j T[t]}^{c}$ correspond to marginal effects at the mean value of age ${ }_{j T[t]}^{15}$. 


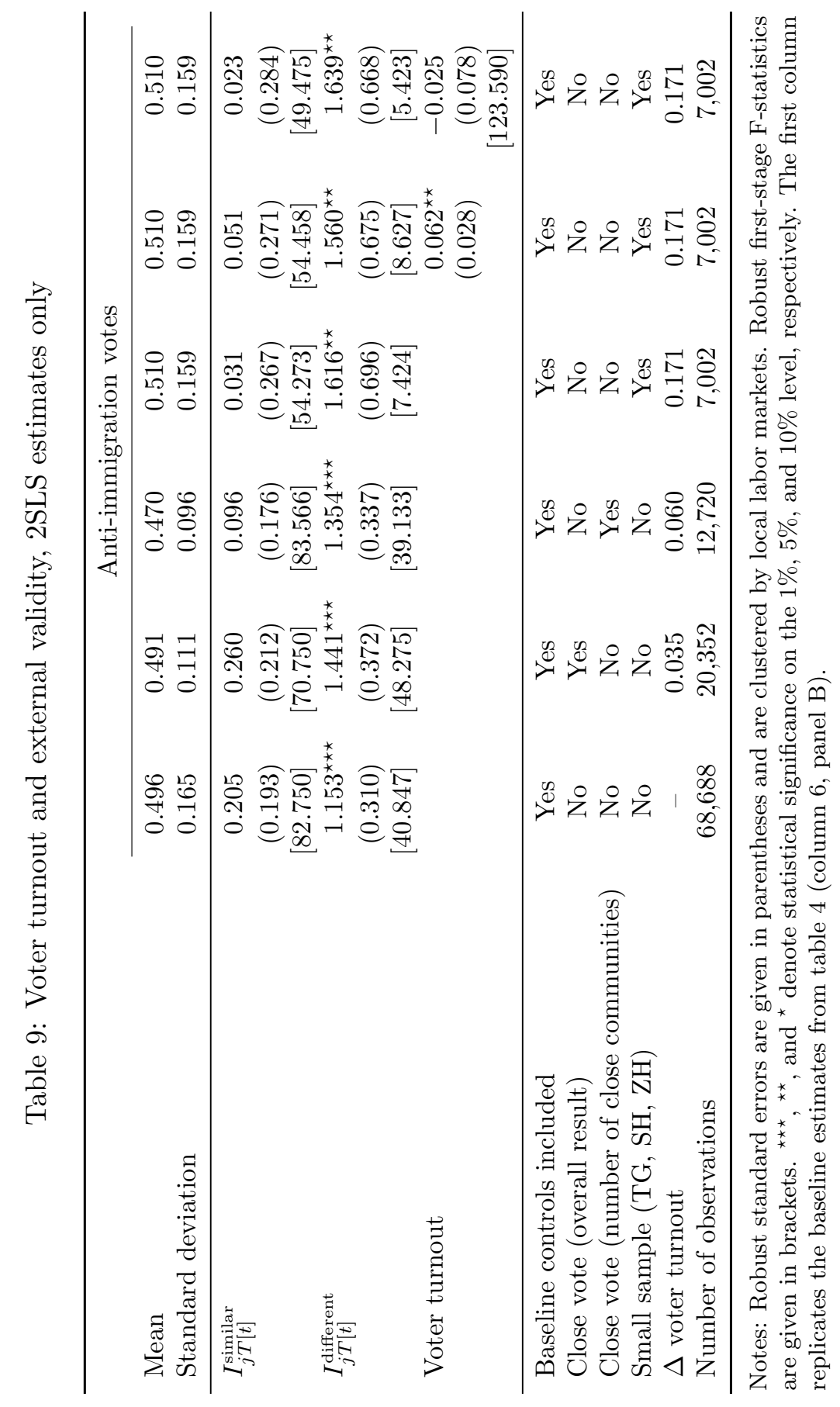




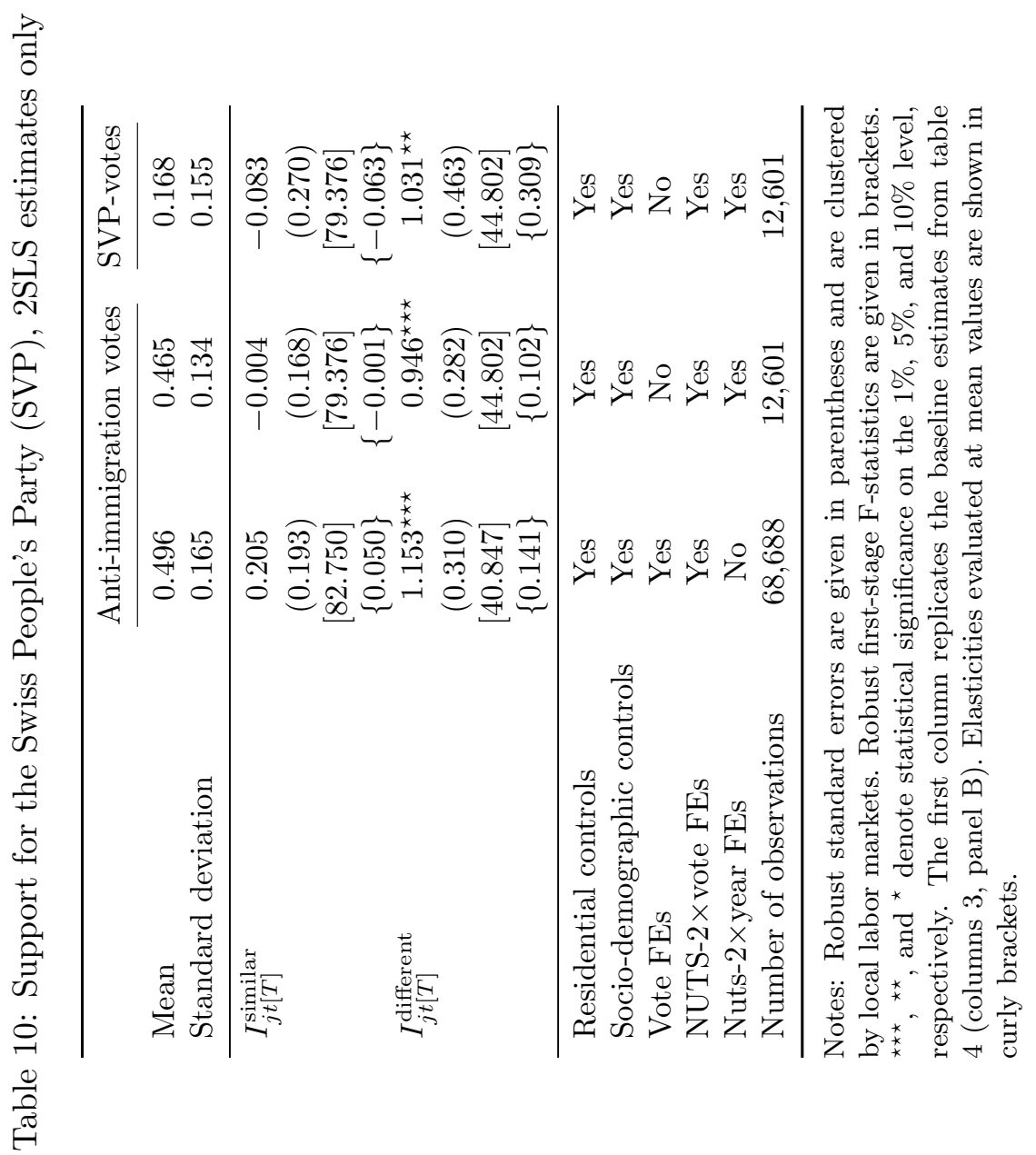



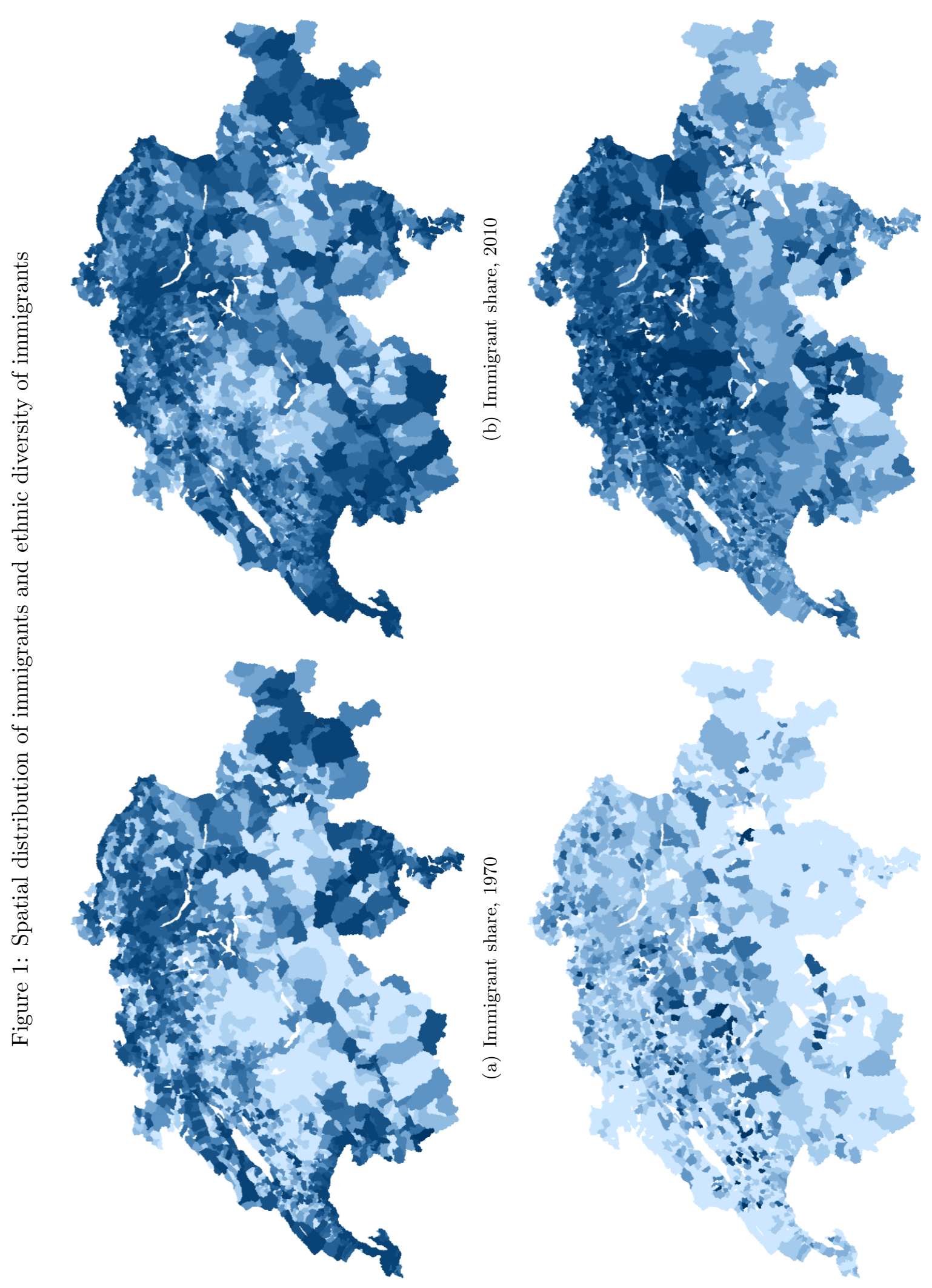

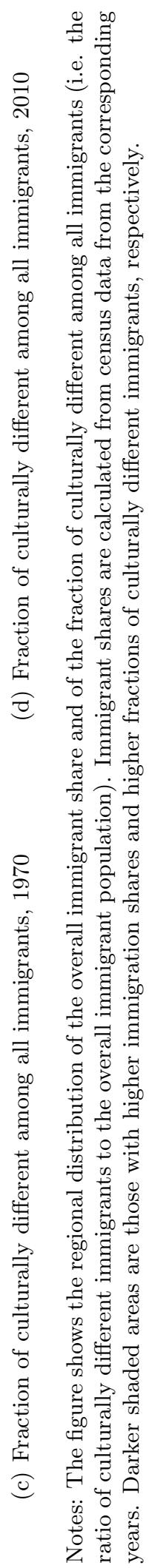




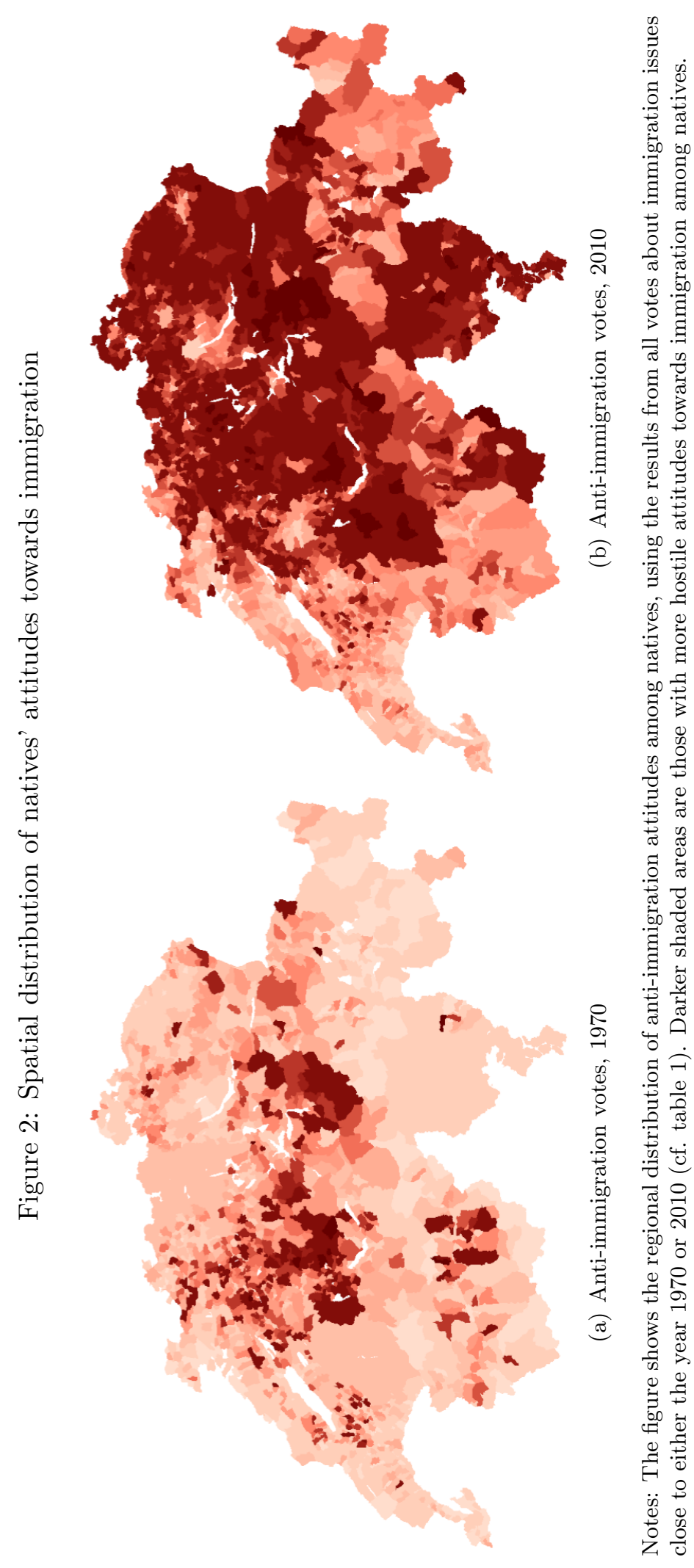


Figure 3: Single-vote results, 2SLS estimates

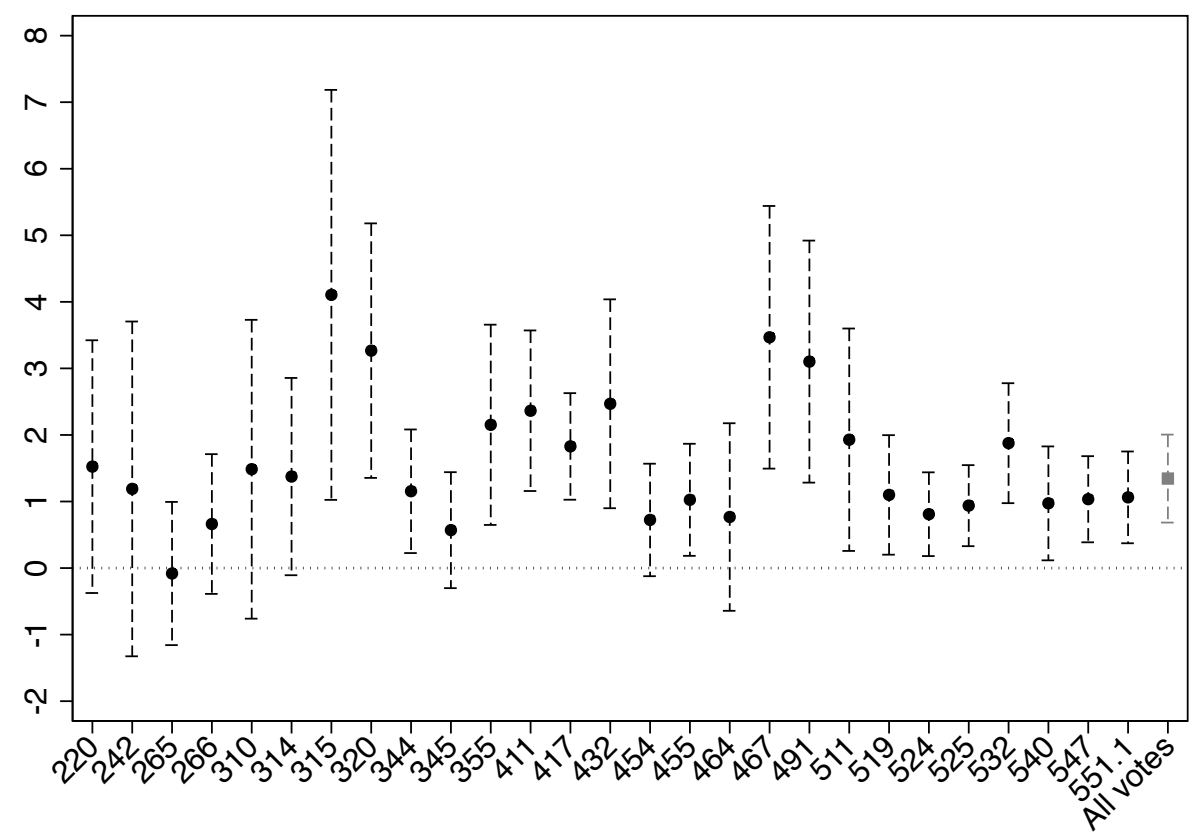

(a) Culturally different immigrants

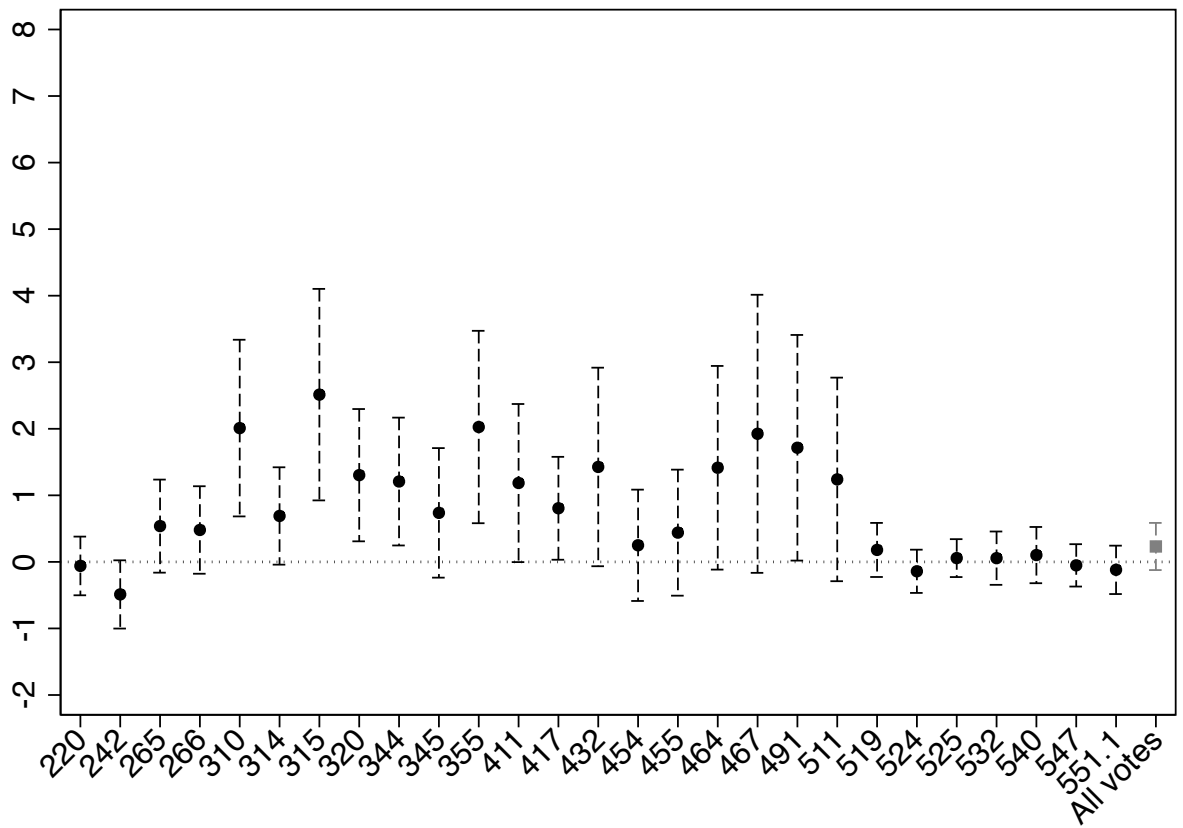

(b) Culturally similar immigrants

Notes: The figure shows 2SLS point estimates, along with their corresponding $95 \%$ confidence intervals, based on robust standard errors and using our baseline specification for each single vote (the vote numbers are shown on the $\mathrm{x}$-axis and they correspond to the numbers used in table 1). The upper (lower) figure shows coefficient estimates of the share of culturally similar immigrants (culturally different immigrants). The rightmost estimate ("All votes") corresponds to our baseline estimates from column 6 of table 4 . 
Figure 4: Estimates by voter-turnout percentile, 2SLS estimates

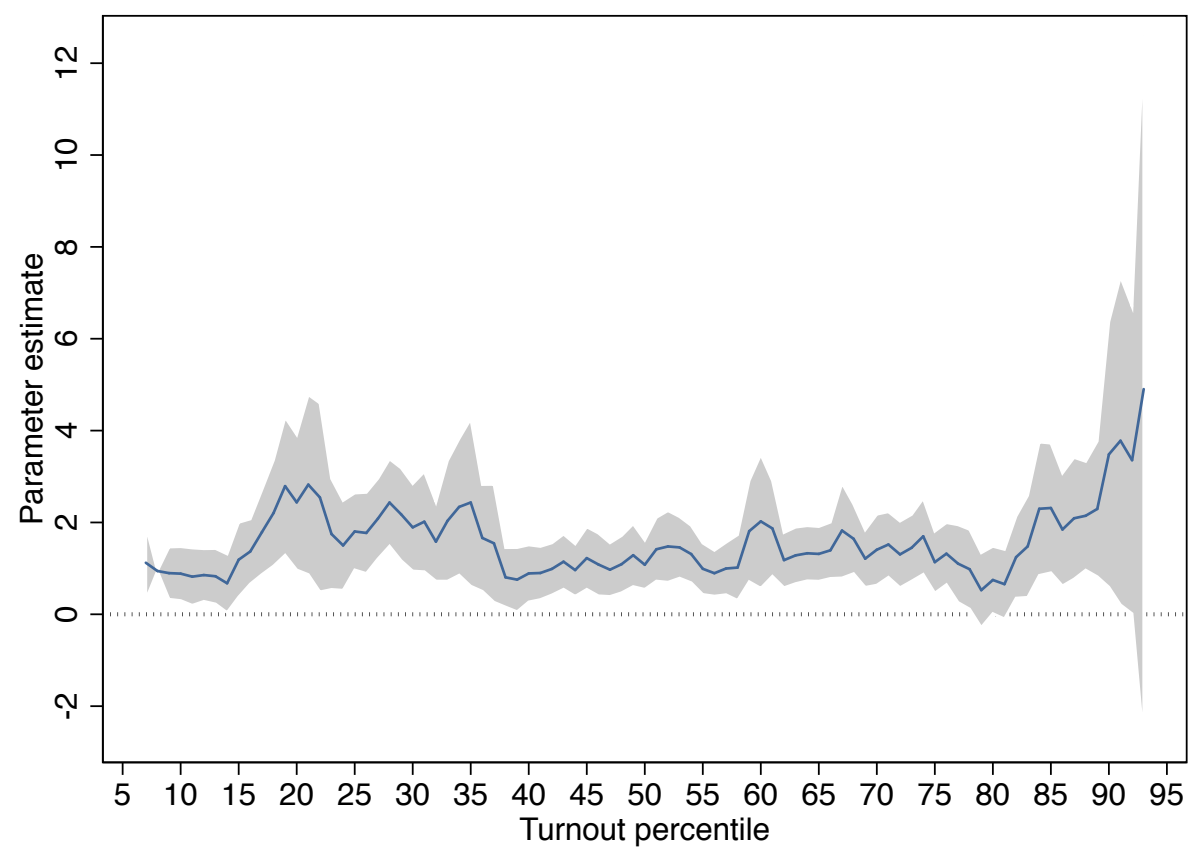

(a) Culturally different immigrants

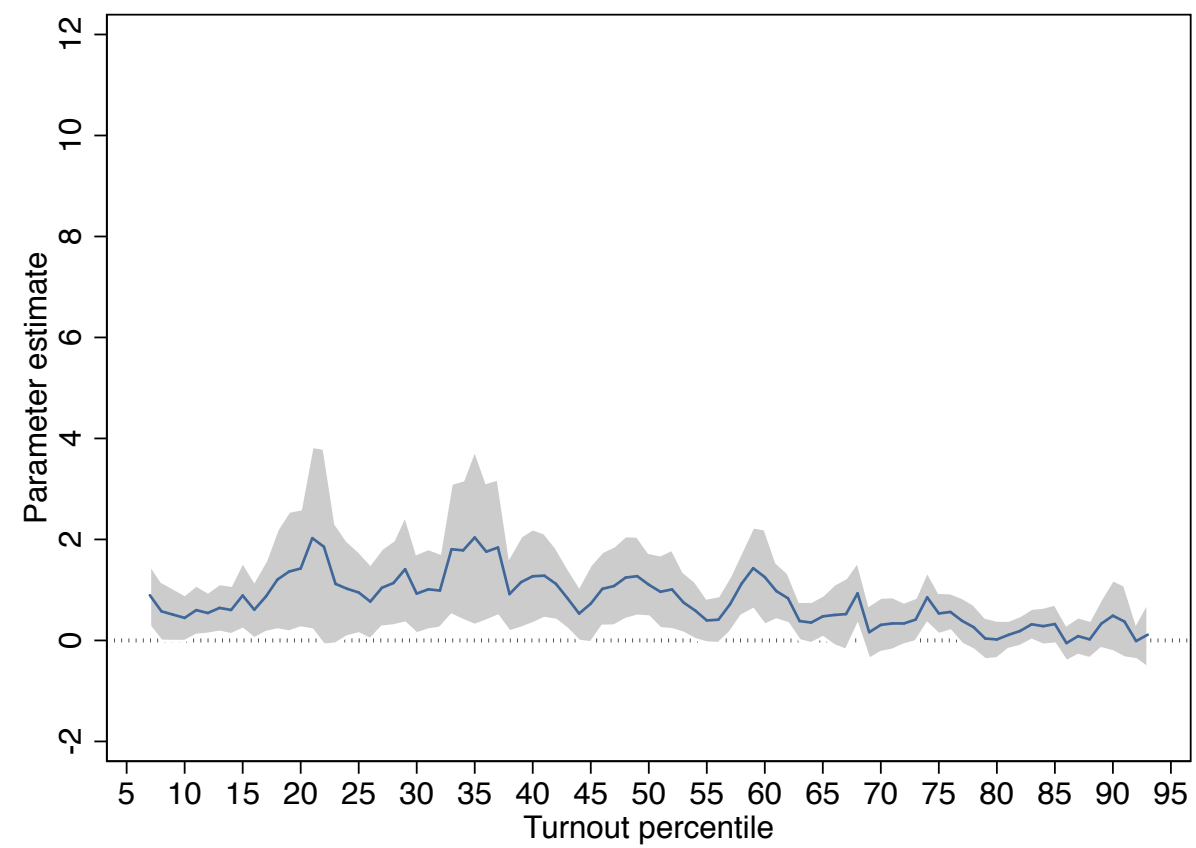

(b) Culturally similar immigrants

Notes: The lines show 2SLS point estimates of the culture-specific immigrant shares using our baseline specification within subsamples defined over voter turnout. The shaded area depicts the corresponding $95 \%$ confidence band (based on robust standard errors). The effects are estimated for each turnout percentile using a moving average over two percentiles. Note that the observed variation of voter turnout ranges from about $30.1 \%$ ( 5 th percentile) to about $81.5 \%$ (95th percentile). 